\title{
GCD2, a Translational Repressor of the GCN4 Gene, Has a General Function in the Initiation of Protein Synthesis in Saccharomyces cerevisiae
}

\author{
MARCO FOIANI, A. MARK CIGAN, CHRISTOPHER J. PADDON, † SATOSHI HARASHIMA, $\ddagger$ \\ AND ALAN G. HINNEBUSCH* \\ Section on Molecular Genetics of Lower Eukaryotes, National Institute of Child Health \\ and Human Development, Bethesda, Maryland 20892
}

Received 18 January 1991/Accepted 27 March 1991

\begin{abstract}
The GCD2 protein is a translational repressor of $G C N 4$, the transcriptional activator of multiple amino acid biosynthetic genes in Saccharomyces cerevisiae. We present evidence that GCD2 has a general function in the initiation of protein synthesis in addition to its gene-specific role in translational control of GCN4 expression. Two temperature-sensitive lethal $\operatorname{gcd} 2$ mutations result in sensitivity to inhibitors of protein synthesis at the permissive temperature, and the gcd2-503 mutation leads to reduced incorporation of labeled leucine into total protein following a shift to the restrictive temperature of $36^{\circ} \mathrm{C}$. The $\mathrm{gcd2}-503$ mutation also results in polysome runoff, accumulation of inactive $80 \mathrm{~S}$ ribosomal couples, and accumulation of at least one of the subunits of the general translation initiation factor $2(\mathrm{eIF}-2 \alpha)$ in $43 \mathrm{~S}-48 \mathrm{~S}$ particles following a shift to the restrictive temperature. The gcd2-502 mutation causes accumulation of 40S subunits in polysomes, known as halfmers, that are indicative of reduced $40 \mathrm{~S}-60 \mathrm{~S}$ subunit joining at the initiation codon. These phenotypes suggest that GCD2 functions in the translation initiation pathway at a step following the binding of eIF-2 . GTP . MettRNA $_{i}^{\text {Met }}$ to $40 \mathrm{~S}$ ribosomal subunits. Consistent with this hypothesis, we found that inhibiting $40 \mathrm{~S}-60 \mathrm{~S}$ subunit joining by deleting one copy $(R P L 16 B)$ of the duplicated gene encoding the 60S ribosomal protein L16 qualitatively mimics the phenotype of $\operatorname{gcd} 2$ mutations in causing derepression of GCN4 expression under nonstarvation conditions. However, deletion of $R P L 16 B$ also prevents efficient derepression of GCN4 under starvation conditions, indicating that lowering the concentration of $60 S$ subunits and reducing GCD2 function affect translation initiation at $G C N 4$ in different ways. This distinction is in accord with a recently proposed model for $G C N 4$ translational control in which ribosomal reinitiation at short upstream open reading frames in the leader of GCN4 mRNA is suppressed under amino acid starvation conditions to allow for increased reinitiation at the $G C N 4$ start codon.
\end{abstract}

In the yeast Saccharomyces cerevisiae, starvation for an amino acid or reduced aminoacyl-tRNA synthetase function leads to increased transcription of over 30 genes encoding amino acid biosynthetic enzymes in 11 different pathways (general amino acid control). This cross-pathway response occurs because synthesis of GCN4 protein, a transcriptional activator of these genes, increases under conditions of amino acid starvation (reviewed in reference 25). GCN4 expression is regulated by amino acid availability at the translational level by a mechanism involving four short upstream open reading frames (uORFs) in the leader of GCN4 mRNA. A subset of these uORFs blocks the flow of scanning ribosomes to the GCN4 start codon under nonstarvation conditions. This translational repression by the uORFs is dependent on trans-acting negative regulators of GCN4 expression encoded by $G C D$ genes. Positive regulators encoded by $G C N 1, G C N 2$, and $G C N 3$ stimulate GCN4 translation in amino acid-starved cells. GCN1, GCN2, and GCN3 appear to act by antagonizing GCD factors because $\mathrm{gcd}$ mutations overcome the requirement for these positive effectors for derepression of GCN4 (25). Recently, mutations have been isolated in the structural genes for the alpha and beta

\footnotetext{
* Corresponding author.

$\dagger$ Present address: Genetics Department, Glaxo Group Research Limited, Greenford, Middlesex, UB6 OHE, England.

$\ddagger$ Present address: Department of Fermentation Technology, Faculty of Engineering, Osaka University, Osaka 565, Japan.
}

subunits of the general translation initiation factor 2 (eIF-2) that derepress GCN4 expression in the same manner described previously for $g c d$ mutations (54). This is one of several observations suggesting that translation of $G C N 4$ mRNA is stimulated under conditions in which general translation initiation is reduced (52).

In addition to causing derepression of $G C N 4$, all known gcd mutations lead to slow growth or temperature-sensitive growth under nonstarvation conditions. Furthermore, deletions of $G C D 1$ and $G C D 2$ are unconditionally lethal (25). Because GCN4 is dispensable under nonstarvation conditions, these findings indicate that GCD factors have an essential function in addition to their roles in general amino acid control. Given their involvement in regulating GCN4 translation, a function in general protein synthesis has been considered a likely possibility. In accord with this notion, the temperature-sensitive lethal gcdl-101 mutation leads to lower rates of incorporation of radiolabeled amino acids (50, 55) and reduced amounts of a translation initiation intermediate containing charged initiator tRNA (52) following a shift to the nonpermissive temperature. In this report, we examine the role of the GCD2 protein in the process of translation initiation.

Considerable genetic evidence exists that the GCN3 protein contributes to the essential functions of GCD1 and GCD2 in addition to its role as a positive regulator of GCN4 translation. For example, certain mutations in GCD2 ( $g c d 2$ 502 and $g c d 2-503$ ) were isolated that overcome the low-level 
GCN4 expression associated with a gcn3-101 mutation, leading to a constitutively derepressed $\left(\mathrm{Gcd}^{-}\right)$phenotype and temperature-sensitive growth under nonstarvation conditions $(20,41)$. Surprisingly, wild-type $G C N 3$ restores both the essential and the negative regulatory functions of $G C D 2$ impaired in these $g c d 2$ mutants. Similar results were obtained for a group of $\mathrm{gcdl}$ mutations isolated as suppressors of $g c n 3-101$ (19), and the temperature-sensitive gcdl-101 mutation is unconditionally lethal in combination with a gcn3 deletion (17). In addition, there is significant amino acid sequence similarity between GCN3 and the carboxyl-terminal half of GCD2, supporting the idea that these two proteins have closely related functions (40). Indeed, recent biochemical studies indicate that GCD1, GCD2, and GCN3 exist in the same high-molecular-weight protein complex $(6 \mathrm{a})$. The latter finding suggests that wild-type GCN3 protein overcomes the mutant phenotypes of the aforementioned gcdl and $g c d 2$ mutations by stabilizing the thermolabile $g c d$ encoded proteins present in the same complex (19). In wild-type cells under starvation conditions, GCN3 is thought to mediate the effects of GCN1 and GCN2 in reducing the functions of GCD proteins with which it associates as the means of stimulating GCN4 translation.

Genetic interactions similar to those just described involving $G C D 1, G C D 2$, and $G C N 3$ have also been noted between GCN3 and SUI2, the structural gene for the alpha subunit of eIF-2. The sui2-1 mutation leads to constitutive derepression of $\mathrm{GCN} 4$ expression ( $\mathrm{Gcd}^{-}$phenotype) and temperaturesensitive growth under nonstarvation conditions and is unconditionally lethal when combined with a deletion of GCN3 (54). This synthetic lethality suggests that GCN3, and by extension GCD1 and GCD2, interact with eIF-2 in carrying out an essential function in translation initiation. The beststudied function of eIF-2 involves the formation of a ternary complex containing GTP and Met-tRNA $A_{i}^{\text {Met }}$ and binding of this complex to a $43 \mathrm{~S}$ species consisting of the small ribosomal subunit and additional initiation factors. The $43 \mathrm{~S}$ preinitiation complex thus formed binds to mRNA and scans the mRNA leader for the AUG start codon, whereupon GTP is hydrolyzed and eIF-2 is released from the ribosome (36). Thus, eIF-2 is directly involved in several reactions of the initiation pathway, any one of which might involve GCD1, GCD2, and GCN3.

In this report we describe the effects of the $\operatorname{gcd} 2-502$ and gcd2-503 mutations on the process of general translation initiation. The results provide strong support for the notion that GCD2 protein is an essential component of the initiation machinery and that the dispensable positive regulator GCN3 contributes to this general function in protein synthesis. Our findings suggest that both $g c d 2$ mutants are impaired in a late step in the translation initiation pathway, following the formation of preinitiation complexes containing eIF-2 and the binding of these complexes to small ribosomal subunits to form $43 \mathrm{~S}$ intermediates. In particular, the gcd2-502 mutant appears to be affected either in scanning, AUG start codon recognition during the scanning process, or the subsequent reactions required for $40 \mathrm{~S}-60 \mathrm{~S}$ subunit joining at the AUG codon. Accordingly, we reasoned that reducing $40 \mathrm{~S}-$ $60 \mathrm{~S}$ subunit joining by lowering the concentration of $60 \mathrm{~S}$ subunits by deleting one copy $(R P L 16 B)$ of the duplicated gene encoding ribosomal protein $\mathrm{L} 16$ should resemble $g c d 2$ mutations in causing derepression of GCN4 expression under nonstarvation conditions. Our results confirm this expectation, supporting the notion that decreasing the efficiency of a late step in the general initiation pathway is responsible for increased translation at GCN4. However, the mutations in GCD2 and RPL16B differ significantly in their quantitative effects on $G C N 4$ expression, and this difference has important implications for the mechanism of GCN4 translational control.

\section{MATERIALS AND METHODS}

Plasmids. Plasmid Ep321 contains GCN3 on a 4.0-kb EcoRI-BamHI fragment isolated from Ep69 (17) and inserted between the EcoRI and BamHI sites of YIp5 (49). Plasmid pM214 was constructed by inserting the $2.5-\mathrm{kb} K p n I$ fragment from p611 (16) containing the $U R A 3$ gene into the KpnI site in the GCN4 coding region of plasmid pAH38 (24). Plasmid pMF12 contains GCD2 on a 2.6-kb ClaI-EagI fragment isolated from pCP46 (41) and inserted between the ClaI and EagI sites of YIp5. Plasmid pCP57 contains the 2.6-kb SalI-EagI fragment from pCP46 inserted between the SalI and EagI sites of YEp24 (5). Plasmids p180, p226, and p227 containing GCN4-lacZ fusions were already described (37). Plasmid pGOBLEU containing the rp5la::LEU2 allele was kindly provided by Nadja Abovich of Brandeis University. Plasmids pl16b $\Delta$ LEU and pY1rA12, containing the rpll6b:: $L E U 2$ and yeast ribosomal DNA repeat unit, respectively, were kindly provided by John L. Woolford of CarnegieMellon University.

Yeast strains. Table 1 lists the yeast strains used. The wild-type $G C D 2$ strains $\mathrm{H} 1453, \mathrm{H} 1459$, and $\mathrm{H} 1457$ were constructed from $\mathrm{H} 952$, H625, and $\mathrm{H} 630$, respectively, by gene replacement using plasmid pMF12 containing the GCD2 gene. The plasmid was digested at the BglII site upstream of $G C D 2$ (40) and used to transform H952, H625, and $\mathrm{H} 630$ to $\mathrm{Ura}^{+}$and temperature resistance $\left(\mathrm{Tsm}^{+}\right)(27)$. Beginning with $\mathrm{Ura}^{+} \mathrm{Tsm}^{+}$transformants, we selected for loss of the plasmid-borne $U R A 3$ gene by the 5-fluoro-orotic acid-positive selection procedure (4). $\mathrm{Ura}^{-}$colonies were purified and screened for the temperature-resistant phenotype indicative of replacement of a $g c d 2$ allele with wild-type $G C D 2$. In the case of $\mathrm{H} 1459$ and $\mathrm{H} 1457$, the strains showed the expected sensitivity to 3-aminotrazole (3-AT; an inhibitor of histidine biosynthesis) associated with gcn3-101 (25). The wild-type GCN3 strains $\mathrm{H} 1462$ and H1458 were constructed from $\mathrm{H} 625$ and $\mathrm{H} 630$, respectively, by gene replacement using plasmid Ep321 containing the GCN3 gene. The plasmid was digested at the HindIII site upstream of $G C N 3$ (17) and used to transform H625 and H630 to Ura ${ }^{+}$. Ura ${ }^{-}$ colonies were isolated as described above and screened for resistance to 3-AT and temperature resistance, indicative of replacement of $g c n 3-101$ with wild-type GCN3. H1456 was a $\mathrm{Ura}^{-}$derivative showing the same phenotype as the parental strain $\mathrm{H} 630$ and thus had retained the gcn3-101 allele. RPL16B in H1402, H1333, and H1511 strains was replaced with the rpll6b::LEU2 deletion/insertion allele, forming strains H1532, H1533, and H1675, respectively, by one-step gene replacement using plasmid pl16b $\Delta \mathrm{LEU}$, as previously described (47). Deletion of RPLI6B was confirmed by DNA blot hybridization analysis (data not shown). H1550 and H1555 were meiotic segregants of a cross between H1532 and EY163 that contain the HIS4-lacZ fusion, the latter being identified by the formation of blue colonies on medium containing 5-bromo-4-choro-3-indolyl- $\beta$-D-galactopyranoside (X-Gal). GCN4 in $\mathrm{H} 1402$ and $\mathrm{H} 1532$ was replaced with a gcn4::URA3 deletion/insertion allele, forming strains $\mathrm{H} 1652$ and $\mathrm{H} 1653$ respectively, by one-step gene replacement using the 3.7-kb BstEII-MluI fragment from pM214 to transform $\mathrm{H} 1402$ and $\mathrm{H} 1532$ to $\mathrm{Ura}^{+}$. Deletion of $G C N 4$ was confirmed by DNA blot hybridization analysis (data not 
TABLE 1. S. cerevisiae strains

\begin{tabular}{|c|c|c|}
\hline Strain & Genotype & Reference or source \\
\hline $\mathrm{H} 4$ & MATa ura3-52 leu2-3 leu2-112 & 17 \\
\hline H64 & 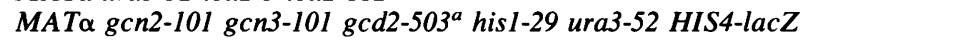 & 20 \\
\hline H96 & 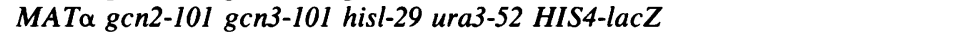 & 20 \\
\hline H625 & MATa gcd2-503 gcn3-101 ura3-52 & 19 \\
\hline H630 & MATa gcd2-502 gcn3-101 ura3-52 leu2-3 leu2-112 & 19 \\
\hline H952 & MAT $\alpha$ gcd2-1 ura3-52 leu2-3 leu2-112 & 41 \\
\hline H1333 & MAT $\alpha$ inol ura3-52 leu2-3 leu2-112 HIS4-lacZ gcn2::URA3 & 16 \\
\hline H1402 & MAT $\alpha$ inol ura3-52 leu2-3 leu2-112 HIS4-lacZ & 16 \\
\hline H1453 & MAT $\alpha$ ura3-52 leu2-3 leu2-112 & This study \\
\hline H1456 & MATa gcd2-502 gcn3-101 ura3-52 leu2-3 leu2-112 & This study \\
\hline H1457 & MATa gcn3-101 ura3-52 leu2-3 leu2-112 & This study \\
\hline H1458 & MATa $g c d 2-502$ ura3-52 leu2-3 leu2-112 & This study \\
\hline H1459 & MATa gcn3-101 ura3-52 & This study \\
\hline H1462 & MATa $g c d 2-503$ ura3-52 & This study \\
\hline H1489 & MAT $\alpha$ inol ura3-52 leu2-3 leu2-112 HIS4-lacZ gcn $3^{c} R 104 \mathrm{~K}$ & 16 \\
\hline H1511 & MAT $\alpha$ ura3-52 trp1-63 leu2-3 leu2-112 GAL2+ & This study \\
\hline H1532 & MAT $\alpha$ inol ura3-52 leu2-3 leu2-112 HIS4-lacZ rp116b::LEU2 & This study \\
\hline H1533 & MAT $\alpha$ inol ura3-52 leu2-3 leu2-112 HIS4-lacZ rp116b::LEU2 gcn2::URA3 & This study \\
\hline H1550 & 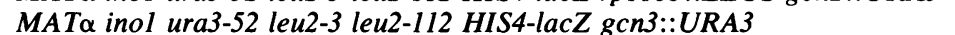 & This study \\
\hline H1555 & MAT $\alpha$ inol ura3-52 leu2-3 leu2-112 HIS4-lacZ rp116b::LEU2 gcn3::URA3 & This study \\
\hline H1652 & MAT $\alpha$ inol ura3-52 leu2-3 leu2-112 HIS4-lacZ gcn4::URA3 & This study \\
\hline H1653 & MAT $\alpha$ inol ura3-52 leu203 leu2-112 HIS4-lacZ rp116b::LEU2 gcn4::URA3 & This study \\
\hline H1654 & MATa inol ura3-52 leu2-3 leu2-112 HIS4-lacZ rp5la::LEU2 & This study \\
\hline H1675 & MAT $\alpha$ ura3-52 trp1-63 leu2-3 leu2-112 GAL2 ${ }^{+}$rp116b::LEU2 & This study \\
\hline EY163 & MATa ura3-52 leu2-3 leu2-112 gcn3::URA3 & E. Hannig \\
\hline TP11B-4-1 & MATa adel leu2-3 leu2-112 ura3-52 prt1-1 & G. Johnston \\
\hline FY14 & MATa ura3-52 trpl $\Delta-63$ & F. Winston \\
\hline
\end{tabular}

${ }^{a}$ The $g c d 2-502$ and $g c d 2-503$ alleles were originally described as $g c d 12-502$ and $g c d 12-503$, respectively, prior to the demonstration that $G C D 12$ and $G C D 2$ are the same gene (41).

shown). The RP51A gene in $\mathrm{H} 1402$ was replaced with a rp51a::LEU2 deletion/insertion allele, forming strain $\mathrm{H} 1654$, by one-step replacement using plasmid pGOBLEU as described previously (2). The deletion of RP51A was confirmed by DNA blot hybridization analysis (data not shown). Strain TP11B-4-1 was kindly provided by Gerry Johnston of Dalhousie University. H1511 was derived from a genetic cross between $\mathrm{H} 1402$ and FY14 (the latter kindly provided by Fred Winston of Harvard Medical School). EY163 was kindly provided by Ernest Hannig of this laboratory.

Measurement of radioactive leucine incorporation into protein. $g c d 2-503$ strain $\mathrm{H} 64$ and the isogenic GCD2 strain H96 were grown to saturation in SD medium containing the necessary supplements, diluted 1:50 into the same medium, and cultured at $23^{\circ} \mathrm{C}$ for $4 \mathrm{~h}$ to the beginning of exponential growth. $\left[{ }^{3} \mathrm{H}\right]$ leucine was added to $1 \mu \mathrm{Ci} / \mathrm{ml}$, and after $15 \mathrm{~min}$ the cultures were divided in half and placed in water bath shakers at 23 or $36^{\circ} \mathrm{C}$. Aliquots of the cultures were taken at 2-h intervals and assayed for $A_{650}$, as an estimate of cell mass, and for incorporation of radiolabeled leucine into protein as described previously (55).

Antibodies and immunoblot analysis. Rabbit antibodies against GCD2 were generated by using a TrpE-GCD2 fusion protein expressed in Escherichia coli from plasmid pCP50, the construction of which was previously described (40). Induction and extraction of the fusion protein were carried out exactly as described previously (30). The specificity and titer of the serum obtained was determined by immunoblot analysis of crude extracts of transformants of yeast strain $\mathrm{H} 4$ containing single or high-copy-number GCD2 plasmids. Yeast crude extracts were prepared as previously described (11) except that cells were grown in SD medium lacking uracil. Samples $(50 \mu \mathrm{g})$ of total cellular protein were separated by electrophoresis in $10 \%$ sodium dodecyl sulfate- polyacrylamide gels (SDS-PAGE) (32), transferred to nitrocellulose (51), and incubated with a blocking solution of $5 \%$ nonfat dry milk in phosphate-buffered saline (PBS) containing $0.2 \%$ Triton $\mathrm{X}-100$. The filter was incubated overnight at room temperature with total serum diluted 1:500 in blocking solution. The filter was washed four times with PBS, and immunocomplexes were detected by using alkaline phosphatase-conjugated secondary antibodies (Bio-Rad). As shown in Fig. 5 , the serum identified a protein in yeast crude extracts with an apparent $M_{\mathrm{r}}$ of 70,000 , in good agreement with the estimated molecular weight of GCD2 (40). As expected, this protein was present in greater abundance when $G C D 2$ was present on the high-copy-number plasmid pCP57 (see Fig. 5); in addition, we found that gcd 2 mutations specifically reduced the steady-state level of this protein in crude extracts (data not shown). Antibodies against the alpha subunit of eIF-2 were provided by Thomas Donahue of Indiana University.

Preparation and gradient analysis of yeast polysomes and ribosomes. Yeast cultures $(300 \mathrm{ml})$ were grown in YPD at $23^{\circ} \mathrm{C}$ to an optical density at $600 \mathrm{~nm}\left(\mathrm{OD}_{600}\right)$ of 1.0 . One-half of the culture was harvested by centrifugation at room temperature, resuspended in $15 \mathrm{ml}$ of YPD at room temperature, added to $135 \mathrm{ml}$ of YPD prewarmed to $37^{\circ} \mathrm{C}$, and incubated for $30 \mathrm{~min}$ in a $37^{\circ} \mathrm{C}$ water bath shaker. The remaining half of the culture was maintained at $23^{\circ} \mathrm{C}$. At the end of the incubation period, cycloheximide was added at a final concentration of $50 \mu \mathrm{g} / \mathrm{ml}$, and the cultures were placed immediately in ice water. Cells were harvested and washed with $10 \mathrm{ml}$ of ice-cold breaking buffer A $(10 \mathrm{mM}$ Tris- $\mathrm{HCl}$ [pH 7.4], $100 \mathrm{mM} \mathrm{NaCl}, 30 \mathrm{mM} \mathrm{MgCl}_{2}, 50 \mu \mathrm{g}$ of cycloheximide per $\mathrm{ml}, 200 \mu \mathrm{g}$ of heparin per $\mathrm{ml}$ ), centrifuged at 3,600 $\times g$ for $5 \mathrm{~min}$, and resuspended in $1 \mathrm{ml}$ of breaking buffer. Glass beads were added to about one-fourth of the total 
volume and vortexed 10 times for $20 \mathrm{~s}$ with 30-s intervals on ice. The extracts were cleared by two sequential centrifugation steps $(5,000 \times g$ for $5 \mathrm{~min}$ and $12,000 \times g$ for $10 \mathrm{~min})$. Twenty-five $\mathrm{OD}_{260}$ units of supernatant was layered on 12-ml linear 7 to $47 \%$ or 15 to $35 \%$ low-salt sucrose gradients containing $50 \mathrm{mM}$ Tris-acetate ( $\mathrm{pH} 7.0), 50 \mathrm{mM} \mathrm{NH}_{4} \mathrm{Cl}, 12$ $\mathrm{mM} \mathrm{MgCl}$, and $1 \mathrm{mM}$ dithiothreitol and centrifuged in an $\mathrm{SW} 41$ rotor at $4^{\circ} \mathrm{C}$ at $39,000 \mathrm{rpm}$ for 2.5 or $4.5 \mathrm{~h}$, respectively. The gradients were scanned at $254 \mathrm{~nm}$ and fractionated in an ISCO gradient collector, taking $0.2-$ or $0.6-\mathrm{ml}$ fractions. For high-salt sucrose gradients, 7 to $47 \%$ sucrose gradients were prepared with the buffer described above except containing $0.7 \mathrm{M} \mathrm{NaCl}$. $\mathrm{NaCl}$ was added at $0.8 \mathrm{M}$ to the different samples before they were layered on these gradients. For low- $\mathrm{Mg}^{2+}$ gradients, cells were harvested and washed in breaking buffer $\mathrm{B}(50 \mathrm{mM}$ Tris- $\mathrm{HCl}[\mathrm{pH} 7.4], 50$ $\mathrm{mM} \mathrm{NaCl}, 1 \mathrm{mM}$ dithiothreitol), processed as described above, and centrifuged on 7 to $47 \%$ sucrose gradients prepared in breaking buffer $B$.

Proteins were precipitated from $0.60-\mathrm{ml}$ gradient fractions by the addition of $0.2 \mathrm{ml}$ of $50 \%$ trichloroacetic acid (TCA) and incubated overnight at $-20^{\circ} \mathrm{C}$. Proteins were pelleted in a microfuge for $15 \mathrm{~min}$, washed twice with ice-cold acetone, dried under vacuum, and resuspended in $70 \mu$ l of Laemmli loading buffer (32). Samples of $35 \mu \mathrm{l}$ were boiled for $3 \mathrm{~min}$, subjected to SDS-PAGE and analyzed by immunoblotting as described above. Total RNA was precipitated from $0.2-\mathrm{ml}$ gradient fractions by the addition of $0.5 \mathrm{ml}$ of cold ethanol and incubated at $-20^{\circ} \mathrm{C}$ overnight. The RNA was pelleted in a microfuge and purified as described previously (47). RNA samples were lyophilized and resuspended in $50 \mu \mathrm{l}$ of $\mathrm{H}_{2} \mathrm{O}$, and $5 \mu$ l of each was fractionated by electrophoresis in a $1.2 \%$ formaldehyde-agarose gel, transferred to Gene-Screen Plus membrane (Dupont), and probed with ${ }^{32} \mathrm{P}$-labeled pY1rA12 plasmid DNA containing the yeast ribosomal DNA repeat unit (44). Plasmid DNA was labeled by the random primer technique (12). Autoradiograms of the filters were prepared, and the amounts of radiolabeled species were measured with a scanning densitometer (Helena Laboratories Co.).

Assay of HIS4-lacZ and GCN4-lacZ fusions. $\beta$-Galactosidase assays were conducted as described previously (33) on extracts prepared from transformants grown in SD medium containing only the required supplements. For nonstarvation (repressing) conditions, saturated cultures were diluted 1:50 and harvested in mid-exponential phase after $6 \mathrm{~h}$ of growth. For starvation (derepressing) conditions, cultures were grown for $2 \mathrm{~h}$ under nonstarvation conditions and then for 6 $\mathrm{h}$ after 3-AT was added to $10 \mathrm{mM}$. $\beta$-Galactosidase activities were expressed as nanomoles of $o$-nitrophenyl- $\beta$-D-galactopyranoside hydrolyzed per minute per milligram of protein.

\section{RESULTS}

gcd2 mutants are sensitive to inhibitors of translation. To investigate whether GCD2 has a general role in translation, we began by testing gcd 2 mutants for sensitivity to cycloheximide and neomycin, both of which inhibit translation elongation in vitro. At low concentrations, cycloheximide specifically inhibits translation initiation $(3,8,22,42)$. As shown in Table 2, the gcd2-1 GCN3 strain H952, gcd2-502 gcn3-101 strain H1456, and gcd2-503 gcn3-101 strain H625 are all temperature sensitive for growth on nutrient-rich medium (YPD) relative to their respective isogenic wild-type GCD2 strains H1453, H1457, and H1459. As expected from previous findings (19), the temperature-sensitive growth
TABLE 2. Sensitivity of $g c d 2$ mutants to neomycin and cycloheximide

\begin{tabular}{llcccc}
\hline \multirow{2}{*}{ Strain } & \multicolumn{1}{c}{$\begin{array}{c}\text { Relevant } \\
\text { genotype }\end{array}$} & \multicolumn{5}{c}{ Growth $^{a}$} \\
\cline { 2 - 6 } & \multicolumn{1}{c}{$23^{\circ} \mathrm{C}^{b}$} & $37^{\circ} \mathrm{C}^{b}$ & $\mathrm{Neo}, 23^{\circ} \mathrm{C}^{c}$ & $\mathrm{Cyh}, 23^{\circ} \mathrm{C}^{d}$ \\
\hline $\mathrm{H}^{2} 52^{e}$ & gcd2-1 GCN3 & + & - & - & - \\
$\mathrm{H} 1453^{e}$ & GCD2 GCN3 & + & + & + & $+/-$ \\
$\mathrm{H} 1456^{f}$ & gcd2-502 gcn3-101 & + & - & - & - \\
$\mathrm{H} 1457^{f}$ & GCD2 gcn3-101 & + & + & + & - \\
$\mathrm{H} 1458^{f}$ & gcd2-502 GCN3 & + & + & + & - \\
$\mathrm{H} 625^{g}$ & gcd2-503 gcn3-101 & + & - & - & - \\
$\mathrm{H} 1459^{g}$ & GCD2 gcn3-101 & + & + & + & + \\
$\mathrm{H} 1462^{g}$ & gcd2-503 GCN3 & + & + & + & + \\
\hline
\end{tabular}

a Strains were replica printed to the indicated media and scored for growth after 2 to 3 days. + , confluent growth; $+/-$, weak growth; - , no visible growth.

$b$ YPD medium containing no drugs.

c YPD medium containing neomycin at $5 \mathrm{mg} / \mathrm{ml}$.

${ }^{d}$ YPD medium containing cycloheximide at $0.1 \mu \mathrm{g} / \mathrm{ml}$.

e Isogenic strains.

${ }^{f}$ Isogenic strains.

${ }^{g}$ Isogenic strains.

associated with $g c d 2-502$ and $g c d 2-503$ was not observed in strains $\mathrm{H} 1458$ and $\mathrm{H} 1462$ that contain the wild-type allele of $G C N 3$. By contrast, the temperature-sensitive phenotype of the $\operatorname{gcd} 2-1$ mutation is expressed independent of the $G C N 3$ allele (41). The $g c d 2$ mutants H952, H1456, and H625 were found to be sensitive to neomycin on YPD medium at the permissive growth temperature of $23^{\circ} \mathrm{C}$ compared with the corresponding isogenic GCD2 strains $\mathrm{H} 1453, \mathrm{H} 1457$, and H1459. Two of these mutants (H952 and H625) also showed sensitivity to a low concentration of cycloheximide on YPD medium at $23^{\circ} \mathrm{C}$. (The cycloheximide sensitivity associated with the $g c d 2-502$ mutation in H1456 could not be assessed because the isogenic wild-type GCD2 strain $\mathrm{H} 1457$ is sensitive to this drug.) For the gcd2-502 and gcd2-503 mutations, whose temperature-sensitive growth phenotypes are not expressed in the presence of wild-type $G C N 3$, we found that the drug sensitivity associated with these mutations was also overcome by wild-type GCN3 (compare the neomycin sensitivity of the gcd2 gcn3-10I strains $\mathrm{H} 1456$ and H625 with that of the corresponding isogenic gcd2 GCN3 strains $\mathrm{H} 1458$ and $\mathrm{H} 1462$ in Table 2). These findings are consistent with the idea that $\operatorname{gcd} 2$ mutations partially impair general protein synthesis at permissive temperatures, conditions in which they lead to derepression of GCN4 translation (20).

gcd2-503 gcn3-101 mutants are temperature sensitive for incorporation of radioactive amino acids into protein. We next compared the ability of isogenic GCD2 gcn3-101 and gcd2503 gcn3-101 strains to incorporate radiolabeled leucine into proteins during growth at $23^{\circ} \mathrm{C}$ and at various times following a shift to the nonpermissive temperature. We focused on the gcd2-503 allele in this analysis because, of the known mutations in $G C D 2$, it has the most severe effect on growth at $36^{\circ} \mathrm{C}$ (data not shown). At $23^{\circ} \mathrm{C}$, the growth rates of the GCD2 gcn3-101 strain $\mathrm{H} 96$ and the gcd2-503 gcn3-101 mutant $\mathrm{H} 64$ were nearly indistinguishable. After being shifted to $36^{\circ} \mathrm{C}$, the $G C D 2$ gcn3-101 strain doubled three times in cell mass $\left(\mathrm{OD}_{650}\right)$ during the first $6 \mathrm{~h}$ of incubation, whereas the gcd2-503 gcn3-101 mutant doubled only once during the same period of time and arrested with an unbudded cell morphology, as reported previously (19) (data not shown). At $23^{\circ} \mathrm{C}$, the rates of $\left[{ }^{3} \mathrm{H}\right]$ leucine incorporation were nearly identical between the gcd2-503 mutant and wild-type GCD2 strains (Fig. 1A). By contrast, the gcd2-503 mutant showed 

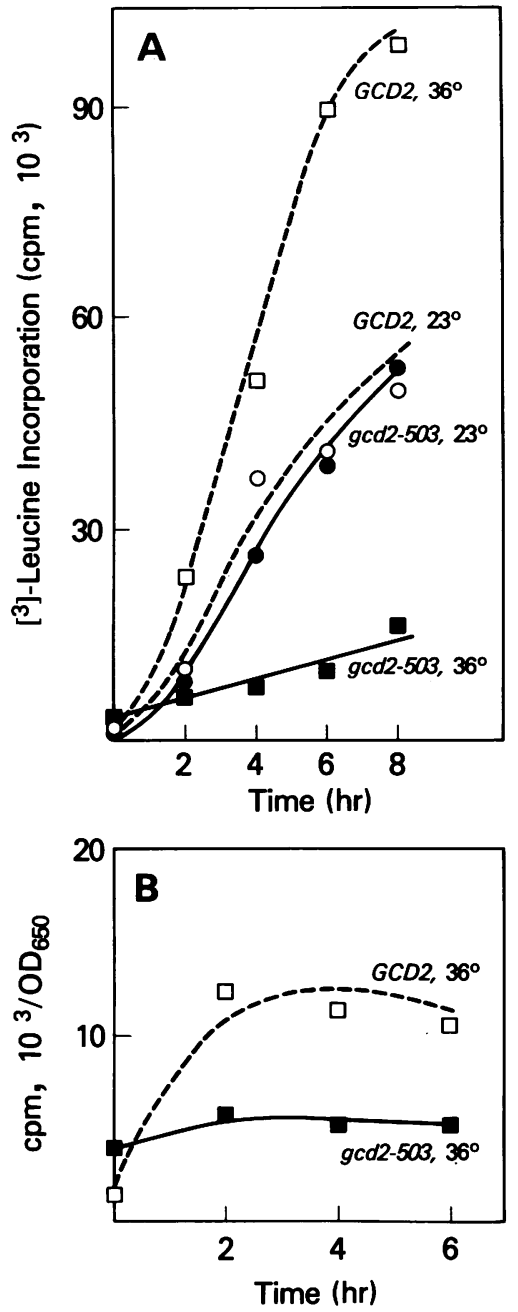

FIG. 1. (A) Incorporation of radioactive leucine into protein in gcd2-503 and GCD2 strains. Exponentially growing cultures of isogenic strains $\mathrm{H} 64$ (gcd2-503 gcn2-101 gcn3-101) and H96 (GCD2 gcn2-101 gcn3-101) were labeled with $\left[{ }^{3} \mathrm{H}\right]$ leucine at $23^{\circ} \mathrm{C}$, and at time zero, one-half of the culture was shifted to $36^{\circ} \mathrm{C}$. Aliquots were taken at 2-h intervals to assay the amount of TCA-insoluble counts per minute, plotted here as a function of time. (B) The counts per minute of $\left[{ }^{3} \mathrm{H}\right]$ leucine incorporated into protein was divided by the $\mathrm{OD}_{650}$ of the culture at each time point for the H96 (GCD2) and H64 ( gcd2-503) cultures incubated at $36^{\circ} \mathrm{C}$. (The comparable curves for the two cultures maintained at $23^{\circ} \mathrm{C}$ were nearly superimposable for H96 and H64.)

a much lower rate of $\left[{ }^{3} \mathrm{H}\right]$ leucine incorporation within the first $2 \mathrm{~h}$ following the shift from 23 to $36^{\circ} \mathrm{C}$ (done at time zero) and throughout the period of incubation at the restrictive temperature than did the wild-type $G C D 2$ strain under the same conditions (Fig. 1A). After normalizing for the $\mathrm{OD}_{650}$ of the cultures, it was evident that at $36^{\circ} \mathrm{C}$, the $G C D 2$ gcn3-101 strain incorporated radioactive leucine at a significantly higher rate per unit cell mass than the gcd2-503 gcn3-101 mutant (Fig. 1B). These findings suggest that the gcd2-503 mutation leads to a rapid reduction in the rate of protein synthesis following a shift to the nonpermissive temperature.

gcd2-503 gcn3-101 mutants exhibit polysome profiles indicative of a reduced rate of translation initiation. In an effort to determine whether translation initiation or elongation was impaired by the gcd2-503 mutation at the nonpermissive temperature, we analyzed polysome profiles in $\operatorname{gcd} 2-503$ gcn3-101 cells before and after a shift from 23 to $37^{\circ} \mathrm{C}$. Figure $2 \mathrm{~A}$ shows the results of sucrose gradient velocity sedimentation of cell extracts isolated from a control strain containing the prtl-1 mutation. Analysis of the effects of this mutation in a cell-free translation system have revealed a specific defect in the ability to bind ternary complexes consisting of eIF-2, GTP, and Met-tRNA ${ }_{i}^{\text {Met }}$ to small ribosomal subunits (13), an early step in the initiation of protein synthesis. When grown at $23^{\circ} \mathrm{C}$, the prt 1-1 strain TP11B-4-1 showed a wild-type sedimentation profile of $80 \mathrm{~S}$ monosomes and polysomes; however, after $15 \mathrm{~min}$ at $37^{\circ} \mathrm{C}$, it exhibited a nearly complete loss of polysomes and a large accumulation of $80 \mathrm{~S}$ particles (Fig. 2A). This effect has been attributed to a greatly reduced rate of initiation coupled with efficient completion of nascent polypeptide chains at the nonpermissive temperature (21). As expected, this runoff of polysomes was shown to be prevented by the addition of cycloheximide prior to the temperature shift at concentrations high enough to block elongation (21).

The gcd2-503 mutation qualitatively resembled the prt l-1 mutation in reducing the polysome/monosome ratio by more than a factor of 2 (from a ratio of 3.0 to 1.3) when the gcd2-503 gcn3-101 mutant $\mathrm{H} 625$ was incubated at $37^{\circ} \mathrm{C}$ for 30 min (Fig. 2B). In addition, the average size of the polysomes remaining at the nonpermissive temperature was less than that of the polysomes present in the same strain grown at $23^{\circ} \mathrm{C}$ (see legend to Fig. 2B). The isogenic GCD2 gcn3-101 strain $\mathrm{H} 1459$ showed no detectable change in either the polysome/monosome ratio or the average size of polysomes when incubated at $37^{\circ} \mathrm{C}$ for $30 \mathrm{~min}$ (Fig. 2C). As shown previously for a prt1-1 mutant (21), addition of cycloheximide prior to the temperature shift eliminated the reduction in polysome content at $37^{\circ} \mathrm{C}$ in $\mathrm{gcd} 2-503 \mathrm{gcn3}-101$ strain H625 (Fig. 2B), implying that translation elongation is required for polysome runoff at $37^{\circ} \mathrm{C}$ in this mutant. Results indistinguishable from those shown in Fig. 2C for GCD2 gcn3-101 strain $\mathrm{H} 1459$ were obtained for the isogenic gcd2503 GCN3 strain H1462 (data not shown), indicating that wild-type GCN3 can overcome the defect in translation initiation evident in strain H625.

Many of the $80 \mathrm{~S}$ particles that accumulate in the gcd2-503 gcn3-101 strain at the nonpermissive temperature appear to be inactive $80 \mathrm{~S}$ couples, in which $40 \mathrm{~S}$ and $60 \mathrm{~S}$ subunits interact in the absence of mRNA, rather than being $80 \mathrm{~S}$ ribosomes engaged in translation. This conclusion follows from the experiment shown in Fig. 3, in which polysomes were fractionated on high-salt sucrose gradients containing $0.7 \mathrm{M} \mathrm{NaCl}$. Under these conditions, 80S couples not associated with mRNA dissociate into $40 \mathrm{~S}$ and $60 \mathrm{~S}$ subunits, whereas $80 \mathrm{~S}$ ribosomes engaged in translation are stable (34, 35). Incubation of $g c d 2-503$ gcn3-101 strain $\mathrm{H} 625$ at the nonpermissive temperature led to a significant accumulation of free $40 \mathrm{~S}$ and $60 \mathrm{~S}$ particles not seen in GCD2 gcn3-101 strain H1459 under the same circumstances. Presumably, $80 \mathrm{~S}$ couples accumulate in $\mathrm{H} 625$ at the restrictive temperature because the initiation factors responsible for preventing subunit association in the absence of mRNA (eIF-3 and eIF-6; 36, 45) are present in smaller amounts than the free ribosomal subunits (6).

In the high-salt gradients shown in Fig. 3, polysomes of different size are not well resolved (35); nevertheless, as in Fig. 2B, it is evident that the average size of polysomes remaining in $\operatorname{gcd} 2-503$ gcn3-101 strain $\mathrm{H} 625$ at $37^{\circ} \mathrm{C}$ was 


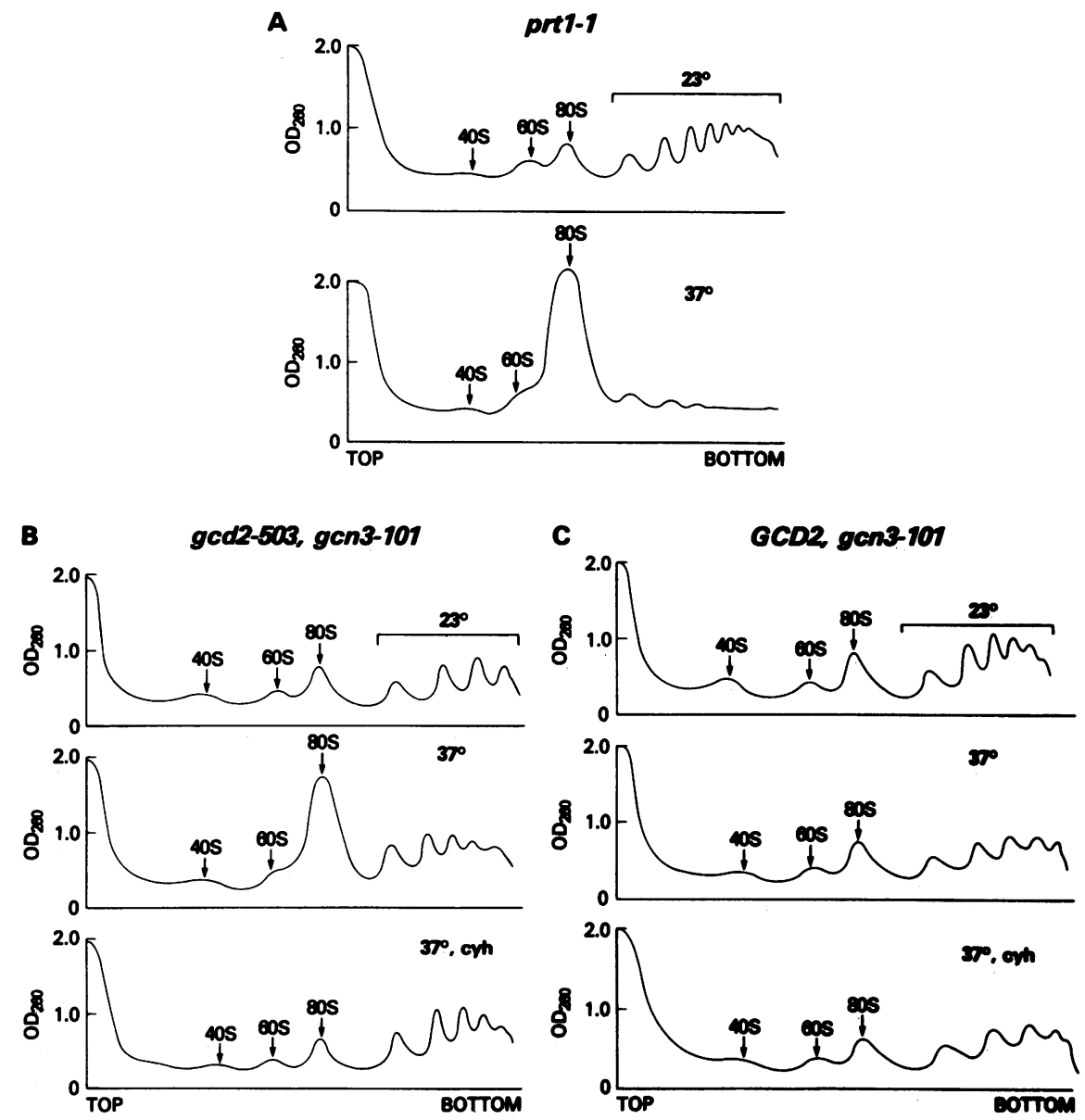

FIG. 2. Analysis of polysome profiles in prt1-1, gcd2-503 gcn3-101, and GCD2 gcn3-101 yeast strains, using low-salt sucrose density gradient centrifugation. Extracts prepared from yeast strains grown in YPD medium at the indicated temperatures were centrifuged on low-salt 7 to $47 \%$ sucrose gradients for $2.5 \mathrm{~h}$ at $39,000 \mathrm{rpm}$. Gradients were fractionated while scanning at $254 \mathrm{~nm}$, and the resulting absorbance profiles are shown, beginning with the top of the gradient on the left. The positions of $40 \mathrm{~S}, 60 \mathrm{~S}$, and 80S ribosomal species are indicated. (A) Polysome profiles of the temperature-sensitive prtl-1 mutant TP11B-4-1 grown at $23^{\circ} \mathrm{C}$ (top gradient) or 15 min after shifting from 23 to $37^{\circ} \mathrm{C}$ (bottom gradient). (B) Polysome profiles of the temperature-sensitive gcd2-503 gcn3-101 strain $\mathrm{H625}$ grown at $23^{\circ} \mathrm{C}$ (top gradient) or after shifting from 23 to $37^{\circ} \mathrm{C}$ for $30 \mathrm{~min}$ (middle gradient). For the bottom gradient, cycloheximide (cyh) was added to the culture just before shifting to $37^{\circ} \mathrm{C}$. (C) Profile of isogenic GCD2 gcn3-101 strain $\mathrm{H} 1459$, analyzed under the same conditions as strain $\mathrm{H} 625$ in panel B. In the " $23^{\circ}$ " gradient of panel $\mathrm{B}, 49 \%$ of the polysomal $\mathrm{OD}_{260}$ was in 2 -mers and 3-mers; this proportion increased to $57 \%$ for the " 37 " gradient. The corresponding values for the " 23 " " and " 37 " gradients for the GCD2 strain in panel C were 47 and $49 \%$, respectively.

significantly less than in the isogenic $G C D 2$ strain $\mathrm{H} 1459$ at the same temperature. RNA blot hybridization analysis of $P Y K 1 \mathrm{mRNA}$ showed no change in the steady-state level of the full-length transcript following the shift to $37^{\circ} \mathrm{C}$ in either strain (data not shown). Therefore, we attribute the reduction in the amount and average size of polysomes seen in the gcd2-503 gcn3-101 mutant to a reduced rate of translation initiation, rather than a general reduction in mRNA synthesis or stability.

Evidence for accumulation of eIF-2 in preinitiation complexes in gcd2-503 gcn3-101 mutants. Another observation consistent with the idea that translation initiation is defective at $37^{\circ} \mathrm{C}$ in a $g c d 2-503$ gcn3-101 mutant is shown in Fig. 4. Antibodies specific for the alpha subunit of eIF-2 (the product of SUI2) were used to localize eIF-2 in low-salt sucrose gradient fractionations of extracts made from the same strains analyzed in Fig. 2B and C. In the GCD2 gcn3-101 strain H1459 incubated at either temperature, and in the $\mathrm{gcd} 2-503$ gcn3-101 mutant $\mathrm{H} 625$ at $23^{\circ} \mathrm{C}$, eIF-2 $\alpha$ was found to be about equally distributed between one pool migrating on the heavy side of the $40 \mathrm{~S}$ peak and another pool spread over several fractions closer to the top of the gradient. The more rapidly sedimenting pool probably represents $43 \mathrm{~S}$ or $48 \mathrm{~S}$ preinitiation intermediates containing eIF2 . GTP - Met-tRNA $A_{i}^{\text {Met }}$ ternary complexes and other initiation factors bound to $40 \mathrm{~S}$ subunits; $48 \mathrm{~S}$ complexes also contain mRNA $(36,46)$. Following the shift to $37^{\circ} \mathrm{C}$ in the gcd2-503 gcn3-101 mutant, we consistently observed an increase in the proportion of the total eIF- $2 \alpha$ that comigrated with the $40 \mathrm{~S}$ subunits, increasing from 22 to $45 \%$ of the total amount present in the gradient for the experiment shown in Fig. 4. This finding suggests that a step in translation initiation following the formation of $43 \mathrm{~S}$ or $48 \mathrm{~S}$ preinitiation complexes is impaired in the $g c d 2$ mutant at the nonpermissive temperature, leading to accumulation of these complexes as reaction intermediates. Interestingly, the same phenomenon shown in Fig. 4 was observed for a temperature-sensitive gcdl-101 mutant that resembles $g c d 2-503$ 
A

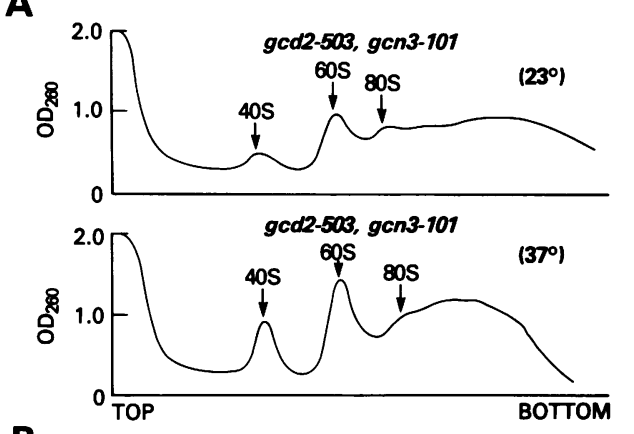

B
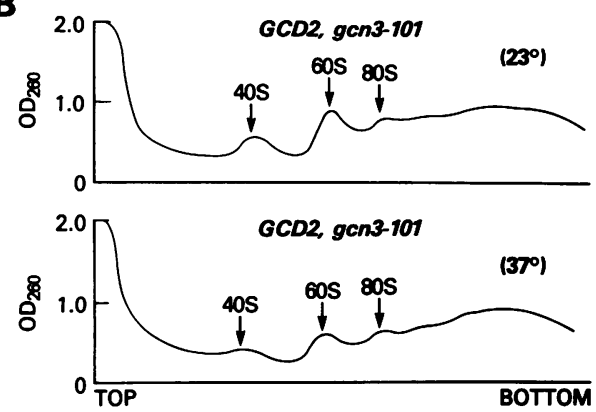

FIG. 3. Analysis of polysome profiles in $\operatorname{gcd} 2-503 \operatorname{gcn} 3-101$ and GCD2 gcn3-101 yeast strains by high-salt sucrose density gradient centrifugation. Extracts prepared from yeast strains grown exactly as described for Fig. 2 were centrifuged on high-salt 7 to $47 \%$ sucrose gradients for $2.5 \mathrm{~h}$ at $39,000 \mathrm{rpm}$ and analyzed as for Fig. 2 . (A) Polysome profiles of gcd2-503 gcn3-101 mutant strain H625; (B) polysome profiles of the isogenic GCD2 gcn3-101 strain H1459.

gcn3-101 strain H625 in showing a reduced polysome content when incubated at the nonpermissive temperature (6a).

When fractions from a low-salt sucrose gradient fractionation of an extract made from GCD2 gcn3-101 strain $\mathrm{H} 1459$ were analyzed by immunoblotting using GCD2-specific antiserum, we consistently found about $10 \%$ of the total GCD2 protein migrating in a peak located on the heavy side of the 40 S ribosomal subunits (Fig. 5), similar in migration to the rapidly sedimenting species of eIF-2 shown in Fig. 4. The remainder of the GCD2 sedimented at approximately $15 \mathrm{~S}$. (The upper band present in the immunoblot of Fig. 5 was judged to be a nonspecific cross-reacting species based on the fact that its abundance was unaffected by increasing $G C D 2$ gene dosage or by $g c d 2$ mutations that destabilize GCD2 protein; data not shown.) Interestingly, the same bimodal distribution shown in Fig. 5 was observed for GCD1 and GCN3, and the $15 \mathrm{~S}$ species has been shown to be a high-molecular-weight complex containing GCD1, GCD2, and GCN3 (6a). The localization of a fraction of GCD2 to the $40 \mathrm{~S}$ region of the gradient, as shown in Fig. 5, supports the notion that GCD2 contributes to the formation or utilization of $43 \mathrm{~S}$ or $48 \mathrm{~S}$ preinitiation complexes. It was not possible to compare the localization of mutant and wild-type GCD2 proteins because the $g c d 2-502$ and $g c d 2-503$ gene products are unstable in cell extracts (data not shown).

Accumulation of halfmer polysomes in $\operatorname{gcd} 2-502 \mathrm{gcn} 3-101$ mutants. Strain H1456 containing the gcd2-502 gcn3-101 double mutation is thermosensitive for growth; however, this phenotype is less severe than that seen for the $g c d 2-503$ gcn3-101 mutant H625 analyzed above (data not shown). Comparison of extracts from isogenic $\operatorname{ccd} 2-502$ gcn3-101 and GCD2 gcn3-101 strains H1456 and H1457, respectively, on
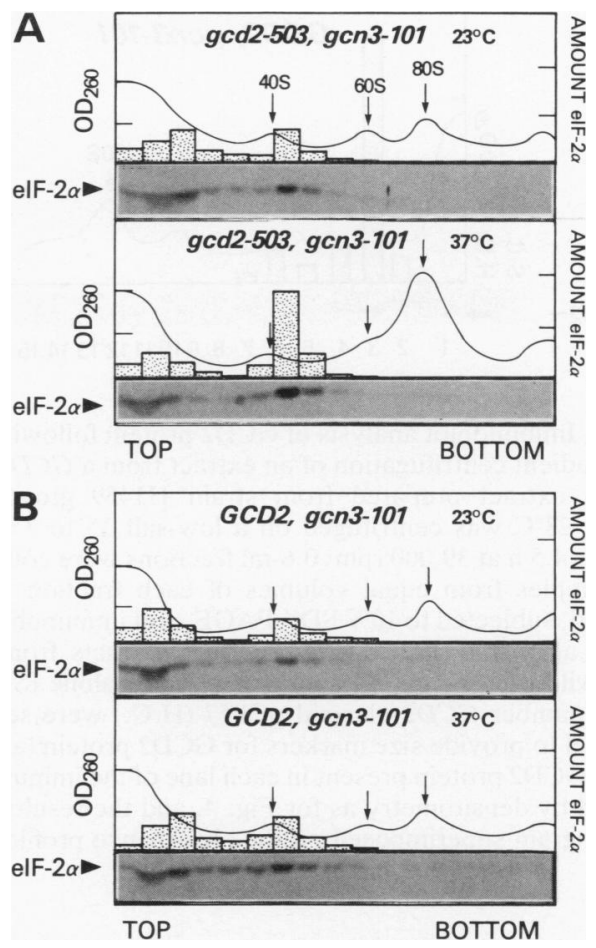

FIG. 4. Immunoblot analysis of eIF- $2 \alpha$ following low-salt sucrose gradient centrifugation of extracts from $g c d 2-503$ gcn3-101 and GCD2 gcn3-101 strains. Extracts prepared from the isogenic strains $\mathrm{H} 625$ and $\mathrm{H} 1459$ grown in YPD medium at $23^{\circ} \mathrm{C}$ or after shifting to $37^{\circ} \mathrm{C}$ for $30 \mathrm{~min}$ were centrifuged on low-salt 15 to $35 \%$ sucrose gradients for $4.5 \mathrm{~h}$ at $39,000 \mathrm{rpm}$. Gradients were fractionated from the top; 0.6-ml fractions were collected. Proteins were precipitated from equal volumes of each fraction, subjected to $10 \%$ SDS-PAGE, and analyzed by immunoblotting using antibodies against eIF-2 $\alpha$. The immunoblot was photographed, and the relative amounts of eIF-2 $\alpha$ in the different fractions were quantitated by densitometry of the negative. The results are shown in the histogram superimposed on the absorbance profile in each panel.

low-salt sucrose gradients revealed two differences with respect to polysomes (Fig. 6A). First, in the gcd2-502 gcn3-101 mutant, the polysome/monosome ratio was only 1.4 , compared with a value of 2.6 measured in the GCD2 gcn3-101 strain. Second, discrete peaks were found migrating between the conventional polysomes. The unusual species present in the gcd2-502 gcn3-101 mutant resemble halfmer polysomes produced by treatment with certain inhibitors of translation initiation that impair 40S-60S subunit joining in the last step of the initiation process (edeine, pactamycin, anisomycin, $\mathrm{NaF}$, and cycloheximide at low concentration; 22, 26, 28, 29, 31, 53). Another situation that leads to halfmer polysomes is a deletion of one of the two genes RPL16A and RPL16B encoding the 60S subunit ribosomal protein L16 (47). This is illustrated in Fig. 6B for mutant strain $\mathrm{H} 1532$ containing the deletion/disruption allele of RPL16B known as rpl16b::LEU2. As shown below, this $r p l 16 b:: L E U 2$ mutant has a higher $40 \mathrm{~S} / 60 \mathrm{~S}$ subunit ratio than is seen for an isogenic wild-type $R P L 16 B$ strain, presumably because of reduced amounts of $60 \mathrm{~S}$ subunits in the mutant. Thus, the formation of halfmers in the rpll6b::LEU2 mutant, and in response to the aforementioned inhibitors of initiation, can both be explained as the result of reduced 40S-60S subunit joining, leading to the accumulation of mRNAbound $43 \mathrm{~S}$ preinitiation complexes (47). 


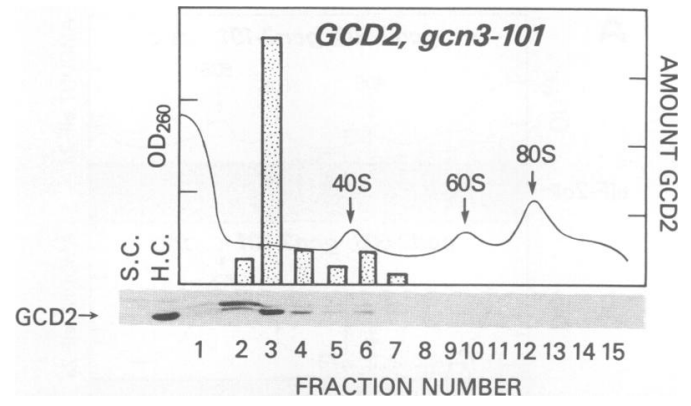

FIG. 5. Immunoblot analysis of GCD2 protein following low-salt sucrose gradient centrifugation of an extract from a GCD2 gcn3-101 strain. An extract prepared from strain $\mathrm{H} 1459$ grown in YPD medium at $23^{\circ} \mathrm{C}$ was centrifuged on a low-salt 15 to $35 \%$ sucrose gradient for $4.5 \mathrm{~h}$ at $39,000 \mathrm{rpm} ; 0.6-\mathrm{ml}$ fractions were collected, and protein samples from equal volumes of each fraction were TCA precipitated, subjected to $10 \%$ SDS-PAGE, and immunoblotted with antibodies against GCD2; $50 \mu \mathrm{g}$ of crude extracts from transformants of wild-type strain $\mathrm{H} 4$ containing vector alone (S.C.) or the high-copy-number GCD2 plasmid pCP57 (H.C.) were separated in the same gel to provide size markers for GCD2 protein (arrow). The amount of GCD2 protein present in each lane of the immunoblot was quantitated by densitometry as for Fig. 4, and the results are given in the histogram superimposed on the absorbance profile.

In an effort to demonstrate that the halfmer polysomes which accumulate in gcd2-502 gcn3-101 strain H1456 contain an extra 40S subunit, we determined the relative amounts of $18 \mathrm{~S}$ and $25 \mathrm{~S}$ rRNA in fractions of the sucrose gradient containing the putative halfmer species found on the heavy shoulder of the $80 \mathrm{~S}$ peak. Total RNA was isolated from these fractions and analyzed by blot hybridization analysis using the yeast ribosomal DNA repeat as a hybridization probe (data not shown). The ratio of $18 \mathrm{~S}$ rRNA/25S rRNA measured for the GCD2 gcn3-101 strain H1457 ranged between 0.8 and 1.4 for several different fractions on the heavy side of the $80 \mathrm{~S}$ peak; by contrast, this ratio was significantly greater in the corresponding position of the gradient from the gcd2-502 gcn3-101 mutant, with ratios ranging between 2.3 and 4.0 for the halfmer-containing fractions. These results support the idea that the halfmer polysomes observed in the gcd2-502 gcn3-101 mutant contain 40S ribosomal subunits unassociated with $60 \mathrm{~S}$ subunits, in addition to $80 \mathrm{~S}$ ribosomes. The observation that the halfmer-containing fractions exhibit $18 \mathrm{~S}$ rRNA/25S rRNA ratios more than twofold greater than the normal ratio for $80 \mathrm{~S}$ ribosomes might indicate that more than one free $40 \mathrm{~S}$ subunit is bound to the halfmer polysomes.

Both the reduced polysome/monosome ratio and the presence of halfmer polysomes were observed in the gcd2-502 gcn3-101 strain $\mathrm{H} 1456$ about equally at $23^{\circ} \mathrm{C}$ and after $30 \mathrm{~min}$ of incubation at $37^{\circ} \mathrm{C}$. However, after prolonged incubation of this mutant at $37^{\circ} \mathrm{C}(40$ to $60 \mathrm{~min})$, the total polysome content decreased even further, the halfmer species became less pronounced, and $80 \mathrm{~S}$ particles accumulated (data not shown). These results suggest that polysome runoff is a more severe manifestation of the $\operatorname{gcd} 2-502$ mutation than the formation of halfmers. The isogenic $g c d 2-502 G C N 3$ strain H1458 did not accumulate halfmer polysomes at either temperature (data not shown).

Formation of halfmers in the $\operatorname{gcd} 2-502 \operatorname{gcn} 3-101$ mutant does not result from ribosomal subunit imbalance. The presence of halfmer polysomes containing extra $40 \mathrm{~S}$ subunits in the gcd2-502 gcn3-101 mutant could result from a defect in a
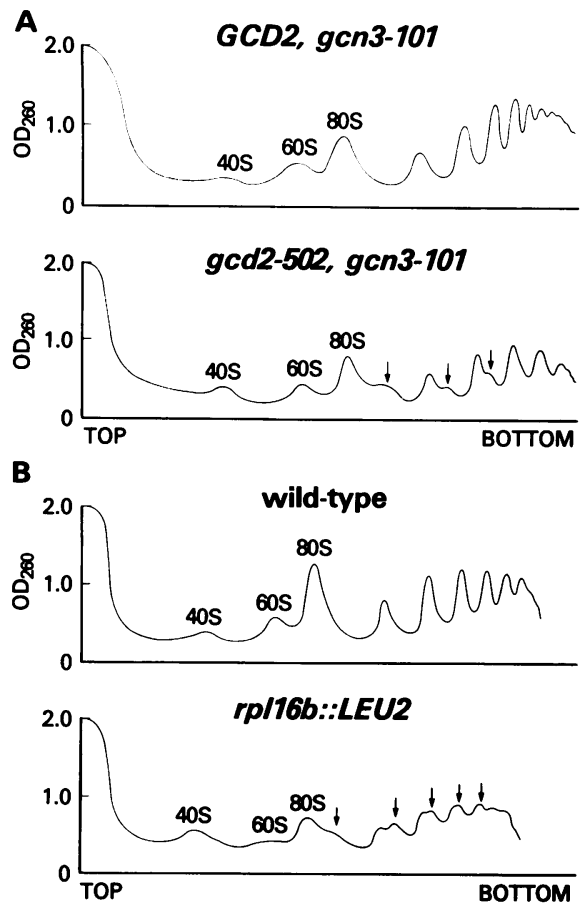

FIG. 6. Analysis of polysomes in gcd2-502 gcn3-101, GCD2 gcn3-101, and rpll6b::LEU2 strains by low-salt sucrose gradient centrifugation. Extracts prepared from yeast strains H1457 (GCD2 gcn3-101) and H1456 (gcd2-502 gcn3-101) (A) and H1402 (RPL16B) and $\mathrm{H} 1532(r p l l 6 b:: L E U 2)(B)$, grown in YPD medium at $23^{\circ} \mathrm{C}$, were centrifuged on low-salt 7 to $47 \%$ sucrose gradients for $2.5 \mathrm{~h}$ at 39,000 $\mathrm{rpm}$ and analyzed as for Fig. 2. The arrows in the bottom part of each panel indicate the halfmer polysomal species.

late step of the initiation pathway, following binding of $43 \mathrm{~S}$ preinitiation complexes to mRNA. Alternatively, it was formally possible that the $\operatorname{gcd} 2-502$ mutation leads to a greater $40 \mathrm{~S} / 60 \mathrm{~S}$ subunit ratio than in wild-type cells, as occurs in rpll6b::LEU2 strains. The latter possibility was eliminated by measuring the relative amounts of $40 \mathrm{~S}$ and $60 \mathrm{~S}$ subunits on sucrose gradients containing low concentrations of $\mathrm{Mg}^{2+}$, in which polysomes and $80 \mathrm{~S}$ ribosomes dissociate into free ribosomal subunits. As shown in Fig. 7A and 7B, the isogenic gcd2-502 gcn3-101 and GCD2 gcn3-101 strains $\mathrm{H} 1456$ and $\mathrm{H} 1457$, respectively, had very similar amounts of $40 \mathrm{~S}$ and $60 \mathrm{~S}$ subunits, and the $40 \mathrm{~S} / 60 \mathrm{~S}$ mass ratio was 0.60 for both strains. By contrast, the rpll6b::LEU2 mutation in strain $\mathrm{H} 1532$ led to an increase in the $40 \mathrm{~S} / 60 \mathrm{~S}$ ratio from 0.6 to 0.8 (Fig. 7C and D). Note that an isogenic strain (H1654) containing a deletion of the small subunit ribosomal protein gene $R P 51 A$ showed a decreased $40 \mathrm{~S} / 60 \mathrm{~S}$ ratio of 0.3 (Fig. $7 \mathrm{E}$ ), presumably because of low levels of RP51 protein and $40 S$ ribosomal subunits (2). On the basis of these findings, we conclude that the presence of halfmer polysomes in the gcd2-502 gcn3-101 mutant is not due to low levels of $60 \mathrm{~S}$ subunits. Rather, it appears to result from a defect late in the initiation pathway following the binding of $43 \mathrm{~S}$ preinitiation complexes to mRNA. We also showed that the $40 \mathrm{~S} / 60 \mathrm{~S}$ mass ratio in the $g c d 2-503$ gcn3-101 strain $\mathrm{H} 625$ was the same either at $23^{\circ} \mathrm{C}$ or following a shift to $36^{\circ} \mathrm{C}$, indicating that the reduced initiation rate seen in this mutant at the nonpermissive temperature does not result from ribosomal subunit imbalance (data not shown).

Deletion of the $60 \mathrm{~S}$ subunit ribosomal protein gene $R P L 16 B$ 


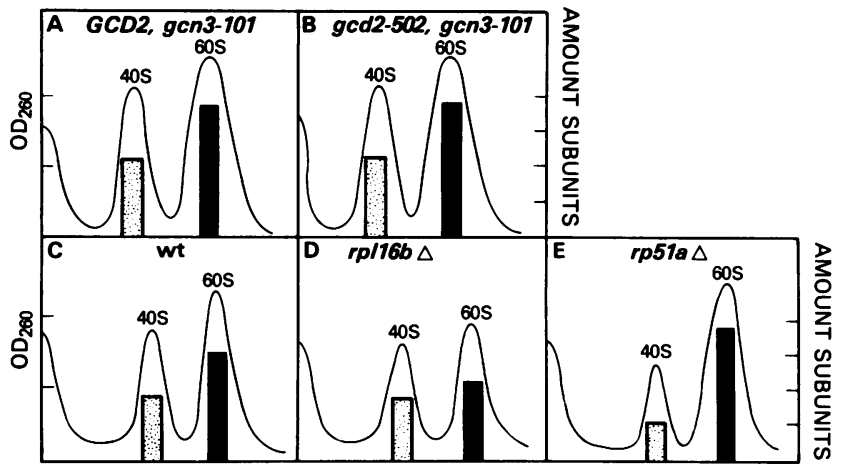

FIG. 7. Analysis of the amounts of $40 \mathrm{~S}$ and $60 \mathrm{~S}$ subunits in wild-type and mutant yeast strains by centrifugation on low- $\mathrm{Mg}^{2+}$ sucrose density gradients. Extracts prepared from the strains indicated below grown in YPD medium at $23^{\circ} \mathrm{C}$ were centrifuged on low- $\mathrm{Mg}^{2+} 7$ to $47 \%$ sucrose gradients for $2.5 \mathrm{~h}$ at $39,000 \mathrm{rpm}$. Gradients were fractionated from the top while scanning at $254 \mathrm{~nm}$, and the total absorbance in the $40 \mathrm{~S}$ and $60 \mathrm{~S}$ peaks is shown by the histograms superimposed on the absorbance profiles. (A) Strain H1457 (GCD2 gcn3-101); (B) strain H1456 (gcd2-502 gcn3-101); (C) strain H1402 (RPL16B); (D) strain H1532 (rpll6b::LEU2); (E) strain H1654 (rp5la::LEU2).

impairs translational control of $G C N 4$. Even though the halfmer polysomes observed in the gcd2-502 gcn3-101 mutant do not result from reduced amounts of $60 \mathrm{~S}$ subunits, it was of interest to know whether the reduced rate of $40 \mathrm{~S}-60 \mathrm{~S}$ joining that occurs in a rpll6b::LEU2 mutant leads to derepression of GCN4 translation, similar to that seen in $g c d$ mutants. This question was of particular interest in view of the model we recently proposed for GCN4 translational control (1) (Fig. 8). According to this model, ribosomes translate $\mathrm{uORF} 1$ and the $40 \mathrm{~S}$ subunits remain attached to the mRNA leader and resume scanning downstream. Under nonstarvation conditions, all of these $40 \mathrm{~S}$ subunits reinitiate at uORFs 2 to 4 and fail to reinitiate at GCN4. Under starvation conditions, or in gcd mutants, many of the $40 \mathrm{~S}$ subunits ignore the start codons at uORFs 2 to 4 and reinitiate at GCN4 instead. This is thought to occur because the reassembly of initiation complexes following termination at UORF1 is slower under starvation conditions and thus requires a greater scanning time. Consequently, a fraction of $40 \mathrm{~S}$ subunits scanning downstream from uORF1 becomes competent to reinitiate only after bypassing uORFs 2 to 4, while scanning the leader sequences between UORF4 and $G C N 4$. A corollary of this model is that the low levels of $60 \mathrm{~S}$ subunits associated with the rpll6b::LEU2 deletion should increase the number of $43 \mathrm{~S}$ preinitiation complexes that scan past uORFs 2 to 4 and reinitiate at GCN4 under nonstarvation conditions ( $\mathrm{Gcd}^{-}$phenotype). Such an effect should be independent of GCN1, GCN2, and GCN3, the positive regulators of GCN4 translation, as these factors are thought to retard the reassembly of an initiation complex, not the availability of $60 \mathrm{~S}$ subunits.

The first observation we made supporting the above corollary was that the rpll6b::LEU2 deletion mimicked gcd mutations in restoring derepression of $H I S 3$ gene expression in gcn 2 and gcn 3 mutants. Mutations in GCN2 and GCN3 prevent derepression of genes encoding enzymes in the histidine pathway that are under the positive control of GCN4, such as HIS3. Consequently, gcn2 and gcn3 mutants are sensitive to 3-AT, an inhibitor of the HIS3 gene product (25). Replacement of RPL16B with the rpll6b::LEU2 deletion allele in gcn2::URA3 strain $\mathrm{H} 1333$ and in gcn3::URA3 strain H1550 suppressed the 3-AT sensitivity associated with the $g c n$ mutations in these strains (Fig. 9). In addition, when the gcn3::URA3 rpll6b::LEU2 leu2 strain $\mathrm{H} 1555$ was
A
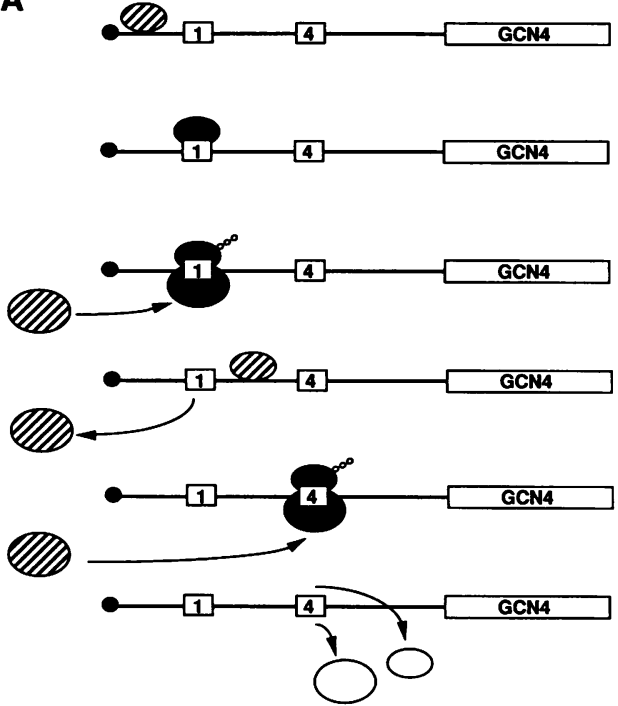

B
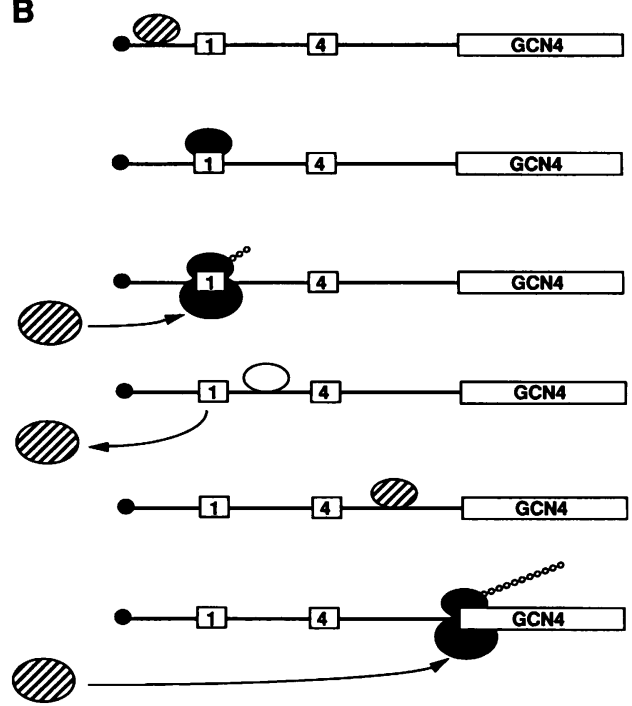

FIG. 8. Model for GCN4 translational control. The GCN4 transcript is shown with uORFs 1 and 4 and the GCN4 coding region depicted as labeled boxes (uORFs 2 and 3 are dispensable for regulation [38]). Large and small ribosomal subunits are shown hatched when they are competent to initiate and solid when elongating; unshaded $40 \mathrm{~S}$ subunits lack one or more factors needed to reinitiate translation. (A) Under nonstarvation conditions, ribosomes translate UORF1 and 40S subunits resume scanning. The necessary initiation factors are reassembled rapidly, and reinitiation occurs efficiently at uORF4. Following termination at this site, both subunits dissociate from the mRNA, preventing translation of GCN4. (B) Under starvation conditions, reassembly of a competent initiation complex following translation of uORF1 occurs more slowly, allowing $50 \%$ of the 40 S subunits to ignore the uORF4 AUG codon; these subunits become competent to reinitiate after scanning the additional sequences in the uORF4-GCN4 interval and initiate translation at GCN4 instead. 

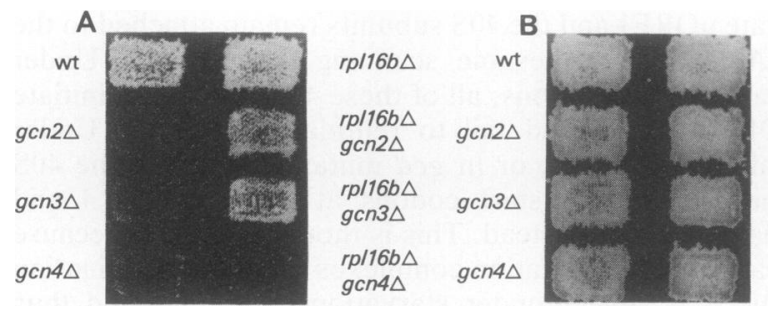

$r p / 16 b \triangle$
$r p / 16 b \Delta$
$g c n 2 \Delta$
$r p / 16 b \Delta$
$g c n 3 \Delta$
$r p / 16 b \Delta$
$g c n 4 \Delta$

FIG. 9. Growth of $g c n$ and $r p l 16 b:: L E U 2$ strains under histidine starvation and nonstarvation conditions. Strains with the indicated relevant genotype were grown on SD medium for 3 days at $30^{\circ} \mathrm{C}$, replica printed to SD containing 3-AT for histidine starvation (A) and to SD for nonstarvation conditions (B), and incubated for 2 days at $30^{\circ} \mathrm{C}$. The following strains were analyzed: wild-type (wt), $\mathrm{H} 1402$; gcn2 $\Delta$, H1333; gcn3 $\Delta, \mathrm{H} 1550 ;$ gcn $4 \Delta, \mathrm{H} 1652 ;$ rpll6b $\Delta, \mathrm{H} 1532$; $r p l 16 b \Delta$ gcn $2 \Delta, \mathrm{H} 1533 ; r p l 16 b \Delta$ gcn $3 \Delta, \mathrm{H} 1555$; and $r p l 16 b \Delta$ gcn $4 \Delta$, H1653.

crossed by gcn3::URA3 RPL16B leu2 strain $\mathrm{H} 1550$ and the resulting diploid was sporulated and subjected to tetrad analysis, we obtained two 3-AT-resistant $\mathrm{Leu}^{+}$and two 3-AT-sensitive $\mathrm{Leu}^{-}$ascospores from each of ten asci dissected. These results suggest that the rpll6b::LEU2 mutation restores derepression of HIS3 expression under starvation conditions in gcn 2 and gcn3 mutants. By contrast, the $r p l 16 b:: L E U 2$ deletion did not suppress the 3-AT sensitivity associated with a $g c n 4:: U R A 3$ mutation (Fig. 9), as expected if the increased $H I S 3$ expression resulting from the $r p l 16 b:$ :LEU2 deletion is mediated by GCN4 protein.

The rpll6b::LEU2 deletion also led to increased resistance to 5-fluorotryptophan (5-FT), a compound that competes with tryptophan for incorporation into proteins but does not trigger the derepression of enzymes subject to the general control (Table 3). gcd mutations result in constitutive enzyme derepression and resistance to 5-FT due to elevated tryptophan levels under nonstarvation conditions $(39,54)$. The 5-FT resistance associated with the rpll6b::LEU2 deletion suggests that this mutation leads to increased expression

TABLE 3. Derepression associated with the rp116b::LEU2 mutation of tryptophan and histidine biosynthetic enzymes independent of GCN2 and GCN3 but dependent on GCN4 function

\begin{tabular}{|c|c|c|c|c|c|}
\hline \multirow[t]{2}{*}{ Strain } & \multirow{2}{*}{ Relevant genotype } & \multicolumn{2}{|c|}{ Growth $^{a}$ on: } & \multicolumn{2}{|c|}{$\begin{array}{l}\text { HIS4-LacZ } \\
\text { activity }^{b}(\mathrm{U})\end{array}$} \\
\hline & & 5-FT & 3-AT & $\mathbf{R}$ & DR \\
\hline $\mathrm{H} 1402^{c}$ & Wild type & $-1+$ & + & 90 & 500 \\
\hline $\mathrm{H} 1532^{c}$ & $r p 116 b:: L E U 2$ & + & + & 230 & 260 \\
\hline $\mathrm{H} 1333^{c}$ & gcn2::URA3 & - & - & 62 & 45 \\
\hline $\mathrm{H} 1533^{c}$ & $r p 116 b:: L E U 2$ gcn2::URA3 & + & + & 210 & 330 \\
\hline H1550 & gcn3::URA3 & - & - & 100 & 66 \\
\hline H1555 & $r p 116 b:: L E U 2$ gcn3::URA3 & + & + & 360 & 240 \\
\hline $\mathrm{H} 1652^{c}$ & gcn4::URA3 & - & - & 40 & 14 \\
\hline $\mathrm{H} 1653^{c}$ & $r p 116 b:: L E U 2$ gcn4::URA3 & - & - & 40 & 19 \\
\hline $\mathrm{H} 1654^{c}$ & rp51a::LEU2 & $-1+$ & + & 88 & 370 \\
\hline H1489 & gcn $3^{c} R 104 K$ & + & + & 960 & 1,000 \\
\hline
\end{tabular}

a Strains were replica printed to 5 -FT $(0.5 \mathrm{mM})$ or 3 -AT $(30 \mathrm{mM})$ medium and scored for growth at $30^{\circ} \mathrm{C}$ after 1 to 2 days. + , confluent growth; $-1+$, very weak growth; - , no visible growth.

${ }^{b} \beta$-Galactosidase activity was assayed under repressing ( $R$, nonstarvation) and derepressing (DR, histidine starvation) conditions. Values are averages of results obtained from assays on two to three independently derived transformants; for each construct, the individual measurements deviate from the average value by $30 \%$ or less.

${ }^{c}$ Isogenic strains.
TABLE 4. Evidence that efficient derepression of GCN4-lacZ in a $r p 116 b:: L E U 2$ mutant requires multiple upstream AUG codons in the GCN4 mRNA leader ${ }^{a}$

\begin{tabular}{|c|c|c|c|c|c|c|c|}
\hline \multirow{3}{*}{ Strain } & \multirow{3}{*}{$\begin{array}{l}\text { Relevant } \\
\text { genotype }\end{array}$} & \multicolumn{6}{|c|}{ GCN4-LacZ activity (U) } \\
\hline & & \multicolumn{2}{|c|}{$\begin{array}{c}\text { p180 } \\
\text { (uORFs } \\
1-4 \text { ) }\end{array}$} & \multicolumn{2}{|c|}{$\begin{array}{c}\text { p226 } \\
\text { (uORF4 } \\
\text { only) }\end{array}$} & \multicolumn{2}{|c|}{$\begin{array}{c}\text { p227 } \\
\text { (no uORFs) }\end{array}$} \\
\hline & & $\mathbf{R}$ & DR & $\mathbf{R}$ & DR & $\mathbf{R}$ & DR \\
\hline H1511 & $R P L 16 B$ & 16 & 130 & 9 & 24 & 720 & 84 \\
\hline H1657 & $r p 116 b:: L E U 2$ & 52 & 72 & 19 & 20 & 1,200 & 1,2 \\
\hline
\end{tabular}

${ }^{a}$ The analysis was conducted as for Table 3 .

of tryptophan biosynthetic enzymes under nonstarvation conditions. This phenotype is not affected by inactivation of $G C N 2$ or GCN3 but is completely dependent on GCN4 (Table 3). In summary, the pattern of resistance to 3-AT and 5-FT associated with the rpll6b::LEU2 deletion indicates that this mutation resembles gcd mutations in causing increased expression of GCN4 and genes under its control in the absence of both amino acid starvation and the positive regulators $G C N 2$ and $G C N 3$.

This conclusion was supported by measuring the expression of a HIS4-lacZ fusion present in the strains analyzed in Table 3. Under nonstarvation conditions (column R), the rpll6b::LEU2 deletion led to 2.5-fold-higher HIS4-lacZ expression in strain $\mathrm{H} 1532$ than in the isogenic $R P L 16 B$ strain H1402 and more than 3-fold-higher HIS4-lacZ expression in the gcn2::URA3 and gcn3::URA3 strains $\mathrm{H} 1533$ and $\mathrm{H} 1555$ than in their respective RPL16B parents $\mathrm{H} 1333$ and H1550. As expected, $r p l 16 b:: L E U 2$ led to no derepression in the gcn4::URA3 strain $\mathrm{H} 1653$ relative to its $R P L 16 B$ parent H1652. Surprisingly, under histidine starvation conditions, the rpll6b::LEU2 deletion led to lower HIS4-lacZ expression in strain H1532 compared with that in the parental RPL16B strain H1402 (Table 3). As a result, HIS4-lacZ was constitutively derepressed at an intermediate level in $\mathrm{H} 1532$. By contrast with the latter findings, gcd mutations (25) and constitutively derepressing alleles of $G C N 3$ (16) generally derepress HIS4-lacZ expression to levels exceeding that seen in wild-type cells grown in the presence of 3-AT (e.g., strain $\mathrm{H} 1489$ in Table 3 ). Deletion of the small subunit ribosomal protein gene $R P 51 A$ from wild-type strain $\mathrm{H} 1402$ had little or no effect on the regulation of HIS4-lacZ: under derepressing conditions, expression was reduced by $25 \%$; however, the derepression ratio remained high $(D R / R=4.1)$ (Table 3). Thus, the partial derepression of HIS4-lacZ expression seen in the rpll6b::LEU2 deletion mutant $\mathrm{H} 1532$ appears to result specifically from insufficient amounts of $60 \mathrm{~S}$ ribosomal subunits.

Measurements of $G C N 4-l a c Z$ expression in the isogenic RPLI6B and rpll6b::LEU2 strains $\mathrm{H} 1511$ and H1657 exhibited the same trends shown in Table 3 for HIS4-lacZ expression, indicating that $r p l 16 b:: L E U 2$ impairs the regulation of amino acid biosynthetic genes by altering GCN4 expression: GCN4-LacZ enzyme activity from plasmid p180 containing the wild-type GCN4 mRNA leader was partially derepressed under nonstarvation conditions in the rpll6b:: LEU2 mutant compared with the RPL16B strain (Table 4). Under starvation conditions, GCN4-lacZ expression was lower in the rpll6b::LEU2 strain than in the wild type. Removal of the first three or all four uORFs from the GCN4 mRNA leader diminished the effects of the rpll6b::LEU2 deletion on GCN4-lacZ expression (Table 4). These latter 
results suggest that $r p l 16 b:: L E U 2$ alters $G C N 4$ expression largely by disrupting the normal mechanism of translational control, as its effects are dependent on the number of uORFs present in the leader (25). The opposing influences of the $r p l 16 b:: L E U 2$ mutation on GCN4 expression under starvation versus nonstarvation conditions will be discussed below in the context of our model for GCN4 translational control.

\section{DISCUSSION}

Function of GCD2 in general translation initiation. GCD2 was first identified as a negative regulator of GCN4 expression that is required for the inhibitory effects of the uORFs on translation initiation at GCN4 under nonstarvation conditions. Because $g c d 2$ mutations overcome the requirement for GCN1, GCN2, and GCN3 for increased translation of GCN4 mRNA, it was proposed that the repressing function of GCD2 is antagonized by these positive-acting factors in amino acid-starved cells (25). Presumably, this antagonism is not complete, as GCD2 is an essential gene (41). Allelespecific interactions between mutations in GCD1 and GCD2 with $G C N 3$ led to the proposal that these positive and negative regulators closely interact in controlling GCN4 expression $(19,40)$. Recent biochemical studies support this proposal in showing that GCD1, GCD2, and GCN3 are present in a high-molecular-weight complex that appears to interact with a specific fraction of the eIF-2 in the cell (6a). The latter finding was presaged by the observation that certain mutations in $S U I 2$ and $S U I 3$, the structural genes for eIF- $2 \alpha$ and eIF-2 $\beta$, respectively, resemble $g c d$ mutations in causing constitutive derepression of $G C N 4$. In addition, the sui2-1 mutation is unconditionally lethal in combination with a gcn3 deletion (54), just as temperature-sensitive lethal mutations in $G C D 1$ and $G C D 2$ are exacerbated by deletion of $\operatorname{GCN} 3(19,17)$. Thus, considerable genetic and biochemical evidence exists that GCD1, GCD2, and GCN3 have general functions in protein synthesis involving eIF-2, in addition to their gene-specific roles in regulating translation of GCN4 mRNA.

The results presented in this report support this conclusion in showing that strains containing temperature-sensitive lethal $g c d 2$ mutations exhibit several phenotypes indicative of defects in general protein synthesis: (i) sensitivity to inhibitors of protein synthesis (Table 2); (ii) reduced incorporation of radioactive leucine into total cell protein (Fig. 1); (iii) polysome runoff and accumulation of eIF-2 $\alpha$ in $43 \mathrm{~S}-48 \mathrm{~S}$ particles (in gcd2-503 gcn3-101 cells) (Fig. 2 to 4); and (iv) halfmer polysomes containing extra $40 \mathrm{~S}$ ribosomal subunits bound to mRNA (in gcd2-502 gcn3-101 cells) (Fig. 6). As discussed below, the latter two phenotypes are consistent with a specific defect at a late step in the translation initiation pathway. These defects were eliminated by replacing gcn3101 with wild-type $G C N 3$, in accord with the idea that under nonstarvation conditions, the positive regulator GCN3 contributes to the essential function of GCD2 in translation initiation.

The presence of halfmer polysomes containing extra ribosomal subunits bound to mRNA in the gcd2-502 gcn3-101 mutant (Fig. 6A) suggests that one of the steps between mRNA binding by the $43 \mathrm{~S}$ preinitiation complex and subunit joining with the $60 \mathrm{~S}$ subunit at the AUG codon occurs less efficiently in this mutant. The impaired step could be scanning or recognition of the AUG codon, hydrolysis of GTP in the ternary complex, release of eIF-2 - GDP, or 40S-60S subunit joining (36). Because one of these steps occurs at a reduced rate, preinitiation complexes persist long enough to be detected on polysomes, forming halfmer species. It is noteworthy that cycloheximide at low concentrations is one of several drugs that inhibit 40S-60S subunit joining and thereby produce halfmer polysomes (22) and, as shown in Table 2, gcd2-1 and gcd2-503 gcn3-101 mutants are sensitive to cycloheximide.

The accumulation of eIF- 2 in the $43 S-48 S$ region seen for the gcd2-503 gcn3-101 mutant at the nonpermissive temperature (Fig. 4) is consistent with the idea that GCD2 contributes to a step in the initiation pathway following the binding of eIF-2 - GTP . Met-tRNA $A_{i}^{\text {Met }}$ ternary complexes to small ribosomal subunits. The gcdl-101 mutation also leads to polysome runoff and accumulation of eIF-2 in the $43 \mathrm{~S}-48 \mathrm{~S}$ region (6a) similar to that shown in Fig. 4 for the gcd2-503 gcn3-101 strain. If we assume that the eIF-2-containing species that accumulate in $g c d 2-503$ gcn3-101 and gcdl-101 mutants at $37^{\circ} \mathrm{C}$ are $48 \mathrm{~S}$ complexes containing mRNA, then gcd1-101, gcd2-502, and $g c d 2-503$ mutations could all lead to defects late in the initiation pathway. In this view, the gcd2-503 and gcd1-101 mutations lead to polysome runoff rather than halfmer formation at the nonpermissive temperature because the rate of initiation is more impaired by these mutations than by $g c d 2-502$. With polysome runoff occurring in the $g c d 2-503$ and $g c d 1-101$ mutants, the accumulated preinitiation complexes would sediment primarily at $48 \mathrm{~S}$ rather than forming halfmer polysomes. A similar effect has been observed in rabbit reticulocyte lysates containing an inhibitor of translation initiation from sea urchin eggs: these lysates are depleted of polysomes and show significant accumulation of $80 \mathrm{~S}$ particles and $48 \mathrm{~S}$ preinitiation intermediates (18). Consistent with this explanation is the fact that the gcd2-502 gcn3-101 mutant exhibits halfmer polysomes at $23^{\circ} \mathrm{C}$ (Fig. 6A) when the growth rate is only slightly lower than that of wild-type cells; however, following prolonged incubation at $37^{\circ} \mathrm{C}$, polysome runoff and $80 \mathrm{~S}$ accumulation become more evident, presumably reflecting a more severe reduction in the rate of translation initiation.

Another observation consistent with a late step in the initiation process being defective in $g c d l$ and $g c d 2$ mutants is the fact that SUI2 and SUI3 mutations with a $\mathrm{Gcd}^{-}$ phenotype (derepressed expression of GCN4) were selected on the basis of their ability to utilize non-AUG start codons at $\operatorname{HIS} 4(7,11,54)$. Thus, these mutations appear to affect a function of eIF-2 involved either in AUG codon recognition during the scanning process or in $80 \mathrm{~S}$ initiation complex formation at the start codon, rather than the formation of ternary complexes or binding of these complexes to small ribosomal subunits. Similarly, the rpll6b::LEU2 deletion mimics gcd mutations in causing derepression of GCN4 expression under nonstarvation conditions (Table 3), and this mutation almost certainly leads to reduced rates of $40 \mathrm{~S}-60 \mathrm{~S}$ joining due to insufficient amounts of $60 \mathrm{~S}$ subunits (Fig. 6 and 7). However, as discussed below, the effect of the $r p l 16 b:$ :LEU2 deletion on GCN4 expression appears to be more complex than that of known gcd and SUI mutations.

Effects of $g c d 2$ mutations on translation of GCN4 mRNA. The possibility that $g c d$ mutations reduce the efficiency of a late step in the initiation pathway has important implications for the mechanism of GCN4 translational control. According to our model (1), under starvation conditions a substantial fraction of $40 \mathrm{~S}$ subunits scanning downstream from uORF1 have not reassembled the factors needed for initiation by the time they reach uORFs 2 to 4 and become competent to reinitiate only after scanning the uORF4-GCN4 interval (Fig. 8). This reassembly process requires more time under starvation conditions than under nonstarvation conditions be- 
cause of reduced activity of one or more initiation factors that must associate with, or modify, the $40 \mathrm{~S}$ subunit as it scans between uORF1 and GCN4. We previously suggested that the level of eIF-2 . GTP . Met-tRNA ${ }_{i}^{\text {Met }}$ ternary complexes or the ability of these complexes to bind to $40 \mathrm{~S}$ subunits would be reduced under starvation conditions, such that a substantial number of subunits will lack ternary complexes when they reach uORF4 (1). This possibility is consistent with the derepressed $\left(\mathrm{Gcd}^{-}\right)$phenotype of certain mutations in SUI2 and SUI3 (54) and the depletion of ternary complexes bound to small ribosomal subunits observed in gcdl-101 mutants at the restrictive temperature or after a nutritional shift-down in wild-type cells (52).

However, the accumulation of mRNA-bound preinitiation complexes (halfmer polysomes) and free $40 \mathrm{~S}$ subunits containing eIF-2 in $g c d 2$ and $g c d 1$ mutants seen in our experiments suggests that derepression of GCN4 involves a reduction in a late step of the initiation pathway, such as recognition of the AUG codon, eIF-2 . GTP hydrolysis to eIF-2 . GDP, release of eIF-2 . GDP at the AUG start codon, or 40S-60S subunit joining. In this view, $40 \mathrm{~S}$ subunits containing eIF-2 - GTP - Met-tRNA $A_{i}^{\text {Met }}$ ternary complexes scanning downstream from $\mathrm{UORF} 1$ have a reduced capacity to complete the formation of an $80 \mathrm{~S}$ initiation complex, increasing the probability of bypassing uORFs 2 to 4 . This deficiency would necessarily diminish with time so that efficient reinitiation at $G C N 4$ would occur after the subunits have scanned the additional sequences in the uORF4-GCN4 interval. For example, interaction of another initiation factor (e.g., eIF-5; 43) with $43 \mathrm{~S}$ complexes scanning downstream from uORF1 might have to occur before joining with a $60 \mathrm{~S}$ subunit could take place at the next start site. eIF-2 would still play an important role in derepression of $G C N 4$ because the formation of $80 \mathrm{~S}$ initiation complexes can occur only after eIF-2 . GDP is released from $43 \mathrm{~S}$ preinitiation intermediates (48).

An initiation factor known as eIF-2B or GEF (guanine nucleotide exchange factor), which is required for recycling of eIF-2 . GDP to eIF-2 - GTP, has been shown to be the target of negative regulation in several cases in which protein synthesis is inhibited in mammalian cells $(23,48)$. In every case, it appears that eIF-2B is inhibited indirectly by phosphorylation of the $\alpha$ subunit of eIF-2. Phosphorylated eIF2 . GDP forms a stable complex with eIF-2B that is inactive for recycling activity. It is intriguing that inhibition of eIF-2B activity in this manner appears to produce an accumulation of free $48 \mathrm{~S}$ complexes and halfmer polysomes, suggesting that a late step in the initiation pathway is impaired $(9,10$, $14,15)$. This has led to the suggestion that eIF-2B is involved in removing eIF-2 . GDP from the ribosome in addition to converting eIF-2 - GDP to eIF-2 . GTP. The fact that gcdl and $\operatorname{gcd} 2$ mutants accumulate initiation intermediates similar to those seen in eIF-2B-inhibited lysates is particularly interesting since the molecular weight of the complex containing GCD1, GCD2, and GCN3 and the association of this complex with eIF-2 raise the possibility that GCD1 and GCD2 are subunits of the yeast equivalent of eIF-2B (6a). If this hypothesis is correct, the GCN2 protein kinase may stimulate GCN4 translation by phosphorylation of eIF-2 or one of the components of the GCD1/GCD2/GCN3 complex, thereby reducing the functions of eIF-2B involved late in the initiation pathway.

Deletion of $R P L 16 B$ and $g c d$ mutations differ in their effects on GCN4 expression. The rpll6b::LEU2 deletion resembles gcd (37) and $g c n 3^{c}$ (16) mutations in causing derepression of GCN4 in the absence of starvation; however, the extent of derepression is smaller for $r p l 16 b:: L E U 2$ than for these other mutations. In addition, under starvation conditions, $r p l l 6 b:$ : $L E U 2$ prevents derepression of $G C N 4$ to the level seen in wild-type cells. Both phenotypes can be accounted for in the context of our model for GCN4 translational control as a consequence of reducing the probability of $40 \mathrm{~S}-60 \mathrm{~S}$ subunit joining during the reinitiation process, not only at uORFs 2 to 4 but at GCN4 as well. The depletion of $60 \mathrm{~S}$ subunits caused by the rpll6b::LEU2 mutation should allow a certain fraction of fully assembled $43 \mathrm{~S}$ preinitiation complexes scanning downstream from uORF1 to scan past each of the uORFs without forming an $80 \mathrm{~S}$ initiation complex. Because uORFs 2 to 4 must all be bypassed to reach $G C N 4$, and because a fraction of the preinitiation complexes that reach GCN4 will likewise fail to initiate there, only a modest increase in GCN4 expression is expected to result from the rpll6b::LEU2 deletion under nonstarvation conditions. In wild-type cells under starvation conditions, many $40 \mathrm{~S}$ subunits scanning downstream from uORF1 have not assembled a preinitiation complex by the time they reach uORFs 2 to 4 and become competent to reinitiate only while traversing the uORF4-GCN4 interval. Therefore, reducing the concentration of $60 \mathrm{~S}$ subunits by the rpll6b::LEU2 deletion should lead to a much smaller increase in the number of preinitiation complexes that reach GCN4 under starvation conditions than under nonstarvation conditions. Moreover, since nearly all of the $40 \mathrm{~S}$ subunits that ignore uORFs 2 to 4 appear to reinitiate at $G C N 4$ (1), the main effect of lowering the level of $60 \mathrm{~S}$ subunits under starvation conditions may be to increase the number of $43 \mathrm{~S}$ preinitiation complexes that bypass the $G C N 4$ start site, thereby reducing translation of $G C N 4$. It is also possible that the rpll6b::LEU2 deletion lowers GCN4 expression under starvation conditions by decreasing the probability of initiation at uORF1, as ribosomes must translate this first uORF in order to reach $G C N 4(1,25)$.

The $g c d$ mutations are thought to reduce the rate at which 40S subunits re-form a preinitiation complex following termination at uORF1. Therefore, the efficiency of reinitiation is differentially affected at uORFs 2 to 4 versus $G C N 4$ due to the greater scanning time involved in reaching the latter start site (1). By contrast, the above explanation suggests that impairing the subunit joining reaction by reducing the concentration of $60 \mathrm{~S}$ subunits in the rpll6b::LEU2 strain lowers the efficiency of reinitiation equivalently at uORFs 2 to 4 and at $G C N 4$, independent of the time required for $40 \mathrm{~S}$ subunits to reach each site. Thus, the difference in the extent of derepression produced by $r p l 16 b:: L E U 2$ and gcd mutations reinforces a central idea of our model, namely, that GCD factors contribute to a time-dependent modification of the $40 \mathrm{~S}$ subunit during the scanning process that readies it for reinitiation downstream from uORF1 (1).

\section{ACKNOWLEDGMENTS}

We thank Thomas Dever, Ernie Hannig, Rosemary Jagus, Charles Moehle, Manuel Ramirez, Ron Wek, and John Woolford for their helpful comments on the manuscript, Kathy Shoobridge for help in its preparation, and our colleagues in the LMG for stimulating discussions. We are grateful to John Woolford, Nadja Abovich, Gerald Johnston, Ernie Hannig, and Paul Miller for gifts of yeast strains and plasmids.

\section{REFERENCES}

1. Abastado, J. P., P. F. Miller, B. M. Jackson, and A. G. Hinnebusch. 1991. Suppression of ribosomal reinitiation at upstream open reading frames in amino acid-starved cells forms the basis for GCN4 translational control. Mol. Cell. Biol. 11:486-496. 
2. Abovich, N., L. Gritz, L. Tung, and M. Rosbash. 1985. Effect of RP51 gene dosage alterations on ribosome synthesis in Saccharomyces cerevisiae. Mol. Cell. Biol. 5:3429-3435.

3. Baliga, B. S., A. W. Pronczuk, and H. N. Munro. 1969. Mechanism of cycloheximide inhibition of protein synthesis in a cell free system prepared from rat liver. J. Biol. Chem. 244:44804489.

4. Boeke, J. D., F. LaCroute, and G. R. Fink. 1984. A positive selection for mutants lacking orotidine-5'-phosphate decarboxylase activity in yeast: 5 -fluoro-orotic acid resistance. Mol. Gen. Genet. 197:345-346.

5. Botstein, D., S. C. Falco, S. E. Stewart, M. Brennan, S. Scherer, D. T. Stinchcomb, K. Struhl, and R. W. Davis. 1979. Sterile host yeasts (SHY): a eukaryotic system of biological containment for recombinant DNA experiments. Gene 8:17-24.

6. Browning, K. S., J. Humphreys, W. Hobbs, G. B. Smith, and J. M. Ravel. 1990. Determination of the amounts of the protein synthesis initiation and elongation factors in wheat germ. J. Biol. Chem. 265:17967-17973.

6a.Cigan, A. M., M. Foiani, E. M. Hannig, and A. G. Hinnebusch. 1991. Complex formation by positive and negative translational regulators of GCN4. Mol. Cell. Biol. 11:3217-3228.

7. Cigan, A. M., E. K. Pabich, L. Feng, and T. F. Donahue. 1989. Yeast translation initiation suppressor sui2 encodes the alpha subunit of eukaryotic initiation factor 2 and shares identity with the human alpha subunit. Proc. Natl. Acad. Sci. USA 86:2784 2788.

8. Cooper, T. G., and J. Bossinger. 1976. Selective inhibition of protein synthesis initiation in Saccharomyces cerevisiae by low concentration of cycloheximide. J. Biol. Chem. 251:7278-7280.

9. De Benedetti, A., and C. Baglioni. 1983. Phosphorylation of initiation factor eIF2alpha, binding of mRNA to $48 \mathrm{~S}$ complexes, and its reutilization in initiation of protein synthesis. J. Biol. Chem. 258:14556-14562.

10. De Benedetti, A., and C. Baglioni. 1984. Inhibition of mRNA binding to ribosomes by localized activation of dsRNA-dependent protein kinase. Nature (London) 311:79-81.

11. Donahue, T. F., A. M. Cigan, E. K. Pabich, and B. CastilhoValavicius. 1988. Mutations at a $\mathrm{Zn}(\mathrm{ll})$ finger motif in the yeast e1F-2 $\beta$ gene alter ribosomal start-site selection during the scanning process. Cell 54:621-632.

12. Feinberg, A. P., and B. Vogelstein. 1984. Addendum: a technique for radiolabeling DNA restriction endonuclease fragments to high specific activity. Anal. Biochem. 137:266-267.

13. Feinberg, B., C. S. McLaughlin, and K. Moldave. 1982. Analysis of temperature-sensitive mutant $t s 187$ of Saccharomyces cerevisiae altered in a component required for the initiation of protein synthesis. J. Biol. Chem. 257:10846-10851.

14. Gross, M., R. Redman, and D. A. Kaplansky. 1985. Evidence that the primary effect of phosphorylation of eukaryotic initiation factor 2 alpha in rabbit reticulocyte lysate is inhibition of the release of eukaryotic initiation factor-2 . GDP from 60S ribosomal subunits. J. Biol. Chem. 260:9491-9500.

15. Gross, M., M. Wing, C. Rundquist, and M. S. Rubino. 1987. Evidence that phosphorylation of eIF-2 $\alpha$ ) prevents the eIF-2Bmediated dissociation of eIF-2 - GDP from the 60S subunit of complete initiation complexes. J. Biol. Chem. 262:6899-6907.

16. Hannig, E. H., N. P. Williams, R. C. Wek, and A. G. Hinnebusch. 1990. The translational activator GCN3 functions downstream from GCN1 and GCN2 in the regulatory pathway that couples GCN4 expression to amino acid availability in Saccharomyces cerevisiae. Genetics 126:549-562.

17. Hannig, E. M., and A. G. Hinnebusch. 1988. Molecular analysis of GCN4, a translational activator of GCN4: evidence for posttranslational control of $G C N 3$ regulatory function. Mol. Cell. Biol. 8:4808-4820.

18. Hansen, L. J., W. Huang, and R. Jagus. 1987. Inhibitor of translational initiation in sea urchin eggs prevents mRNA utilization. J. Biol. Chem. 262:6114-6120.

19. Harashima, S., E. M. Hannig, and A. G. Hinnebusch. 1987. Interactions between positive and negative regulators of $G C N 4$ controlling gene expression and entry into the yeast cell cycle. Genetics 117:409-419.
20. Harashima, S., and A. G. Hinnebusch. 1986. Multiple GCD genes required for repression of $G C N 4$, a transcriptional activator of amino acid biosynthetic genes in Saccharomyces cerevisiae. Mol. Cell. Biol. 6:3990-3998.

21. Hartwell, L. H., and C. S. McLaughlin. 1969. A mutant of yeast apparently defective in the initiation of protein synthesis. Proc. Natl. Acad. Sci. USA 62:468-474.

22. Helser, T. L., R. A. Baan, and A. E. Dahlberg. 1981. Characterization of a $40 \mathrm{~S}$ ribosomal subunit complex in polyribosomes of Saccharomyces cerevisiae treated with cycloheximide. Mol. Cell. Biol. 1:51-57.

23. Hershey, J. W. B. 1989. Protein phosphorylation controls translation rates. J. Biol. Chem. 264:20823-20826.

24. Hinnebusch, A. G. 1984. Evidence for translational regulation of the activator of general amino acid control in yeast. Proc. Natl. Acad. Sci. USA 81:6442-6446.

25. Hinnebusch, A. G. 1988. Mechanisms of gene regulation in the general control of amino acid biosynthesis in Saccharomyces cerevisiae. Microbiol. Rev. 52:248-273.

26. Hoerz, W., and K. S. McCarty. 1971. Initiation of protein synthesis in a rabbit reticulocyte lysate system. Biochim. Biophys. Acta 228:526-535.

27. Ito, H., Y. Fukada, K. Murata, and A. Kimura. 1983. Transformation of intact yeast cells treated with alkali cations. J. Bacteriol. 153:163-168.

28. Kappen, L. S., and I. H. Goldberg. 1976. Analysis of the two steps in polypeptide chain initiation inhibited by pactamycin. Biochemistry 15:811-818.

29. Kappen, L. S., H. Suzuky, and I. H. Goldberg. 1973. Inhibition of reticulocyte peptide-chain initiation by pactamycin: accumulation of inactive ribosomal initiation complexes. Proc. Natl. Acad. Sci. USA 70:22-26.

30. Kleid, D. G., D. Yansura, B. Small, D. Dowbenko, D. M. Moore, M. J. Grubman, P. D. McKercher, D. O. Morgan, B. H. Robertson, and H. L. Bachrach. 1981. Cloned viral protein vaccine for foot-and-mouth disease: responses in cattle and swine. Science 214:1125-1129.

31. Kozak, M., and A. J. Shatkin. 1978. Migration of 40 S ribosomal subunit on messenger RNA in the presence of edeine. J. Biol. Chem. 253:6568-6577.

32. Laemmli, U. 1970. Cleavage of structural proteins during the assembly of the head of bacteriophage T4. Nature (London) 227:680-685.

33. Lucchini, G., A. G. Hinnebusch, C. Chen, and G. R. Fink. 1984. Positive regulatory interactions of the HIS4 gene of Saccharomyces cerevisiae. Mol. Cell. Biol. 4:1326-1333.

34. Martin, T. E. 1973. A simple general method to determine the proportion of active ribosomes in eukaryotic cells. Exp. Cell Res. 80:496-498.

35. Martin, T. E., and L. H. Hartwell. 1970. Resistance of active yeast ribosomes to dissociation by $\mathrm{KCl}$. J. Biol. Chem. 245: 1504-1508.

36. Moldave, K. 1985. Eukaryotic protein synthesis. Annu. Rev. Biochem. 54:1109-1149.

37. Mueller, P. P., S. Harashima, and A. G. Hinnebusch. 1987. A segment of GCN4 mRNA containing the upstream AUG codons confers translational control upon a heterologous yeast transcript. Proc. Natl. Acad. Sci. USA 84:2863-2867.

38. Mueller, P. P., and A. G. Hinnebusch. 1986. Multiple upstream AUG codons mediate translational control of GCN4. Cell 45: 201-207.

39. Niederberger, P., M. Aebi, and R. Huetter. 1986. Identification and characterization of four new GCD genes in Saccharomyces cerevisiae. Curr. Genet. 10:657-664.

40. Paddon, C. J., E. M. Hannig, and A. G. Hinnebusch. 1989. Amino acid sequence similarity between GCN3 and GCD2, positive and negative translational regulators of GCN4: evidence for antagonism by competition. Genetics 122:551-559.

41. Paddon, C. J., and A. G. Hinnebusch. 1989. gcd12 mutations are gcn3-dependent alleles of GCD2, a negative regulator of GCN4 in the general amino acid control of Saccharomyces cerevisiae. Genetics 122:543-550.

42. Palmer, E., J. Wilhelm, and F. Sherman. 1979. Phenotypic 
suppression of nonsense mutants in yeast by aminoglycoside antibiotics. Nature (London) 277:148-150.

43. Peterson, D. T., B. Safer, and W. C. Merrick. 1979. Role of eukaryotic initiation factor 5 in the formation of $80 \mathrm{~S}$ initiation complexes. J. Biol. Chem. 254:7730-7735.

44. Petes, T. D., L. M. Hereford, and K. G. Skryabin. 1978. Characterization of two types of yeast ribosomal DNA genes. J. Bacteriol. 134:295-305.

45. Raychaudhuri, P., E. A. Stringer, D. M. Valenzuela, and U. Maitra. 1984. Ribosomal subunit antiassociation activity in rabbit reticulocyte lysates. J. Biol. Chem. 259:11930-11935.

46. Rhoads, R. E. 1988. Cap recognition and the entry of mRNA into the protein synthesis initiation cycle. Trends Biochem. Sci. 13:52-56.

47. Rotenberg, M. O., M. Moritz, and J. L. Woolford, Jr. 1988. Depletion of Saccharomyces cerevisiae ribosomal protein L16 causes a decrease in $60 \mathrm{~S}$ ribosomal subunits and formation of half-mer polyribosomes. Genes Dev. 2:160-172.

48. Sonenberg, N. 1990. Measures and countermeasures in the modulation of initiation factor activities by viruses. New Biol. 2:402-409.

49. Struhl, K., D. T. Stinchomb, S. Scherer, and R. W. Davis. 1979. High frequency transformation of yeast: autonomous replication of hybrid DNA molecules. Proc. Natl. Acad. Sci. USA
76:1035-1039.

50. Szczesna, E., and W. Filipowicz. 1980. Faithful and efficient translation of viral and cellular eukaryotic mRNAs in a cell-free S-27 extract of Saccharomyces cerevisiae. Biochem. Biophys. Res. Commun. 92:563-569.

51. Towbin, H., T. Staehelin, and J. Gordon. 1979. Electrophoretic transfer of proteins from polyacrylamide gels to nitrocellulose: procedure and some applications. Proc. Natl. Acad. Sci. USA 83:4849-4853.

52. Tzamarias, D., I. Roussou, and G. Thireos. 1989. Coupling of GCN4 mRNA translational activation with decreased rates of polypeptide chain initiation. Cell 57:947-954.

53. Van Venrooij, W. J., J. Van Eenbergen, and A. P. M. Janssen. 1977. Effect of anisomycin on the cellular level of native ribosomal subunits. Biochemistry 16:2343-2348.

54. Williams, N. P., A. G. Hinnebusch, and T. F. Donahue. 1989. Mutations in the structural genes for eukaryotic initiation factors 2alpha and 2beta of Saccharomyces cerevisiae disrupt translational control of GCN4 mRNA. Proc. Natl. Acad. Sci. USA 86:7515-7519.

55. Wolfner, M., D. Yep, F. Messenguy, and G. R. Fink. 1975. Integration of amino acid biosynthesis into the cell cycle of Saccharomyces cerevisiae. J. Mol. Biol. 96:273-290. 